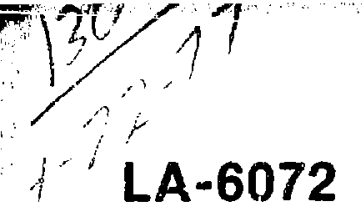

UC.34

Issued: September 1976

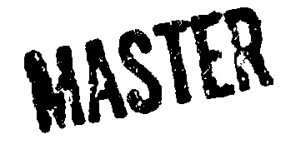

\title{
Bremsstrahlung-Induced K Fluorescence
}

by

Ellery Storm

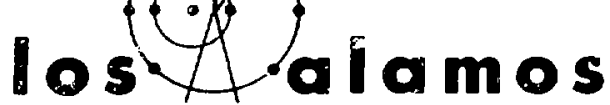

scícintific laboralory

of the University of California

LOS ALAMOS. NEV MEXICO 47545

$\downarrow$

An Affirmative Action / Equal Opportunity Employer 
Printed in the United States of America. Available from National Technical Information Service

U.S. Department of Commerce

5285 Port Royal Road

Springfield, VA 2216

Price: Printed Copy \$4.00 Microfiche \$2.25

Thin repor: was prepared an an accuunt of wark xponaored

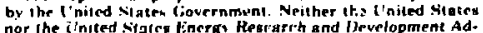

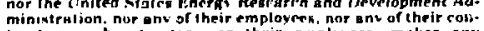

truetarn. aubsentructors. or thrir empluyees. mateft any

wervanty express or implied. or essumes a nv legal liability or

remponsthich

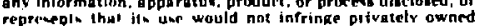

rights. 


\title{
YUEMSTRAHLUNG-INDUCED K FLUORESCENCE
}

\author{
by \\ Ellery Storm
}

\begin{abstract}
Bremsstrahling radiation cun be used to excite searly monoenergetic $x$ rays in seconidary targets, which are then used to study the energy response of radiation detectors if the intensity and purity are known. A method is suggested for calculating the spectral intensity of the secondary target radiation, including $K$-fluorescent $x$ rays, and the bremsstrahlung and characteristic line radiation scattered from the target. Coherent and incoherent scutter are included in the calculation.

To test the theory, bremsstrahlung radiation from an $x$-ray unit operating in the 100 - to $3(0)-k$ potential range was used to excite $K$-fluorescent radiation in secondary targets that range in atomic number from 29 to 90 . The prirnary and secondary spectra were measured with $\mathrm{NaI}$, gilicon, and gernıanium detectors. The measured primery spectral intensities were used as input to the secondary spectral intensity calculation. Calculated secondary spectra were within $20 \%$ agreement with measurement.

Optimization of the secondary target intensity and purity is discussed as a function of target thickness, potential, and selective filtration.
\end{abstract}

\section{INTRODUCTION}

$\mathrm{K}$-17uorescent $\mathrm{x}$ rays excited in a secondary target by photons from the primary target of an $x$-ray tube have been used to obtain monoenergetic sources in the 1 - it $100-\mathrm{keV}$ energy range. 1.3 Fluorescent sources, which have been used for microradiography of histologic sections ${ }^{4}$ and for metallurgical microradiography," have found widespread use in energy response measurements of radiation detectors $^{6-1 .:}$ and as a method of elemental analysis. ${ }^{14}$ The radiation emiited by the secondary target consists not only of $K$-fluorescent $x$ rays but also includes the scattered bremsstrahlung contaminant. Consequeritly, in most applications, one is interested in the purity of the beam as well as the absolute intensity of tie K-fluorescent $x$ rays. Purity is defined as the ratio of $\mathrm{K}$ photons to total number of photons integrated over the energy spectrum. Purity aud intensity can be measured with a photon spectrometer, but it would be useful and of theoretical interest to be able $\vdots 0$ calculate the spectrum and learn how to adjust the variables to optimize purity and intensity. However, one must first know the primary target spectrum, including both the bremsstrahiung continuum and the characteristic line radiation, to calculate the secondary iarget spectrum.

In this report, the primary target brensstrahlung and characteristic line radiction are measureci, and a method is suggested for calculating the secondary target $\mathrm{K}$ fluorescence and scattered bremsstrahlung 
and characteristic line radiation. To test its validity, the method was applied to a specific case. A commercial $x$-ray unit with a tungsten-target tube was used as the primary source. With the $x$-ray tube operating in the 100 - to $300-\mathrm{kV}$ range, intensity as a function of photon energy was measured with a photon spectrometer. Secondary targets, varying in atomic number from 29 to 90 , were irradiated by the primary source in a fixed geometry. Radiation from the secondary target was also measured with a photon spectrometer and the results were compared with the calculated spectra.

Measurements of the primary target radiation have been reported. ${ }^{15}$ This report describes the secondary target spectral measurements, discusses the method of calculating the $K$ fluorescence and scattered bremsetrahlung and characteristic line radiation, and compares the measurements with calculations. Coherert and incoherent scattering are included in the calculations. K-fluorescent intensity and purity are studied as a function of excitation potential, target thickness, and atomic number.

\section{MEASUREMENT}

\section{A. Primary Target Radiation}

The primary source was a constant-potential North American Philips Company Norelco MG-300 industrial $x$-ray unit containing an oil-immersed Müller Mö 301/10 tube. The tungsten target was at a $22^{\circ}$ angle from the central ray and projected a 5 . $\mathrm{mm}$-square focal spot. The accelerating potential could be varied from 100 to $300 \mathrm{kV}$ and the current from $2 \mathrm{t} \cap 10 \mathrm{~mA}$. The Müller tube had a relatively large amount of inherent filtration, consisting of 0.44 $\mathrm{g} / \mathrm{cm}^{2}$ beryllium, $0.65 \mathrm{~g} / \mathrm{cm}^{2}$ Fyrex, $1.4 \mathrm{~g} / \mathrm{cm}^{2}$ oil, and $0.71 \mathrm{~g} / \mathrm{cm}^{2}$ Araldit plastic.

With the Norelco $x$-ray unit operating at 100,150 , 200,250 , and $300 \mathrm{kV}$, spectral measurements were made with silicon and germanium semiconductors and a NaI scintillator. ${ }^{15}$ Because each detector distorts a spectrum differently, it was necessary to use H. I. Israel's program ${ }^{16}$ to obtain a representation of the undistorted spectra. After estimating the undistorted spectrum, the program uses Morite Carlo techniques to distort the spectrum in the same manner as a detector of specified composition, geometry, and resolution.
A first estimate of the undistorted spectra was obtained from theoretical considerations. ${ }^{17.18}$ The first estimate was distorted by the larael program, compared to measurement, then revised to bring it more nearly into egreement with measurement. The second estimate was distorted by the program and then compared to measurement. Further revisions were made, and the process was repeated until satisfactory agreement with measurement was achieved.

Figure 1 shows the final estimate of the undisioried spectra, which agree within $10 \%$ with the spectral measurements obtained with all three detector types. Because the $K$-lines and $K$-edge discontinuity were present in the first estimate derived from theory, these same features appear in the undistor. ted spectra. The spectra in Fig. 1 are free of detector attenuation and distortion but are attenuated by inherent filtration. These spectral distributions are taken to represent the true primary spectral distribution incident on the secondary fluorescent targets.

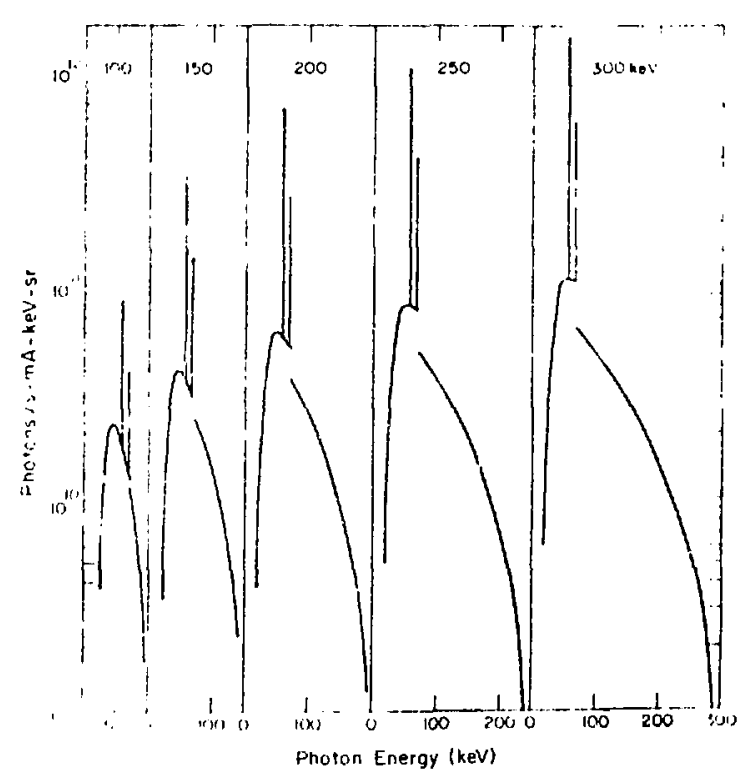

Fig. 1.

Undistorted "measured" spectra. 


\section{B. Secondary Target Radiation}

\section{Experimental Arrangement and Procedure.} Figure 2 shows the arrangement for irradiating the secondary targets to produce K-fluorescent radiation. The primary source was the Norelco unit described above. Except for the exit window, the tube head was completely encased in a $2.5-\mathrm{cm}$-thick itad shield mounted vertically on a turntable. A beam-limiting lead diaphragm with a tapered conical hole was attached to the exit window. Pcsitioned against the exit window diaphragm was a lead-lined brass cylinder that served as a holder for the secondary targets and also absorbed the transmitted primary beam. The targets were placed in the primary beam through a slit in the top of the cylinder. The secondary target, with its center $15 \mathrm{~cm}$ from the primary target, was at a $45^{\circ}$ angle to the central ray of the primary beam. The K-fluorescent bearn passed through a $2.2-\mathrm{cm}$ hole in the brass cylinder. An elect rically actuated shutter in front of the first diaphragm permitted the fluorescent beam to be stopped without turning off power to the $x$-ray tube. A $3.0-\mathrm{cm}$-diam beam-limiting diaphragm was located $8 \mathrm{~cm}$ from the first diaphragm. Aluminum filters were placed over this second diaphragm to absirb $L x$ rays prod,.ed in the targets.

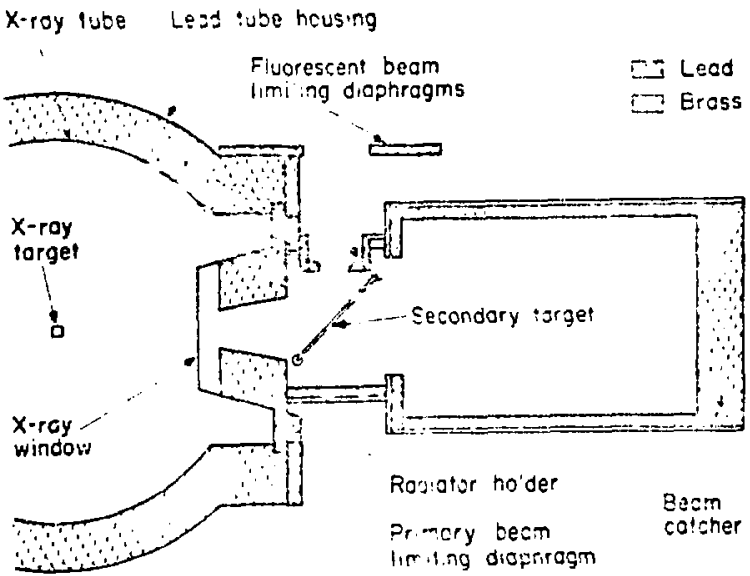

Fig. 2.

Arrangement for irradiating secondary targets to produce $K$-fluorescent radiation.
Table I ists the 10 targets and their thicknesses. The targess were cut or pressed into 5 -cm-diam disks. Target thicknesses were at least $1 \mathrm{mfp}$ thick for their $K \times$ riys. $K$ radiation was assumed to consist of two lines with the combined weighted average of $K_{a}$ plus $K_{b}$ rinergies. The filters used to absorb the $L$ lines produced in the target are also given in the table. $K$ lines produced in the lighter elements of the compounds whro $<3 \mathrm{keV}$ and were absorbed by the aluminum filter..

Spectra from the secondary target were measured with essentialiy the same arrangement used with the primary targ( 1 (Fig. 3). Detectors were located $49 \mathrm{~m}$ from the tarten with an evacuated Orangeburg pipe between the source and detector. The ends of the pipe were (øvered with $0.0105 \cdot g / \mathrm{cm}^{2}$-thick Mylar windows. Air between the secondary target and first Mylar window, air in the pipe, and air between the second Mylar window and detector totaled 0.047 $\mathrm{g} / \mathrm{cm}^{2}$ in thickress. The silicon, germanium, and $\mathrm{Nul}$ detectors used in the primary target measurements were also used in the secondary target measurement.s. Each of thetie detectors distorts ari $\mathrm{x}$ ray spectrum differently, and each has its advan. tages and limitations; these will be discussed when the experimental results are presented.

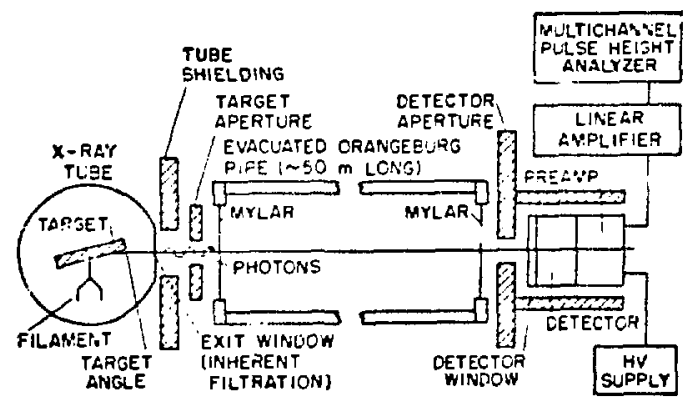

Fig. 3.

Experinental arrangement for the measurement of $x$-ray spectra. 
K-LINE ENERGIES, THICKNESSES, AND L-LINH ¿ZSORBERS

OF SECONDARY TARGETS

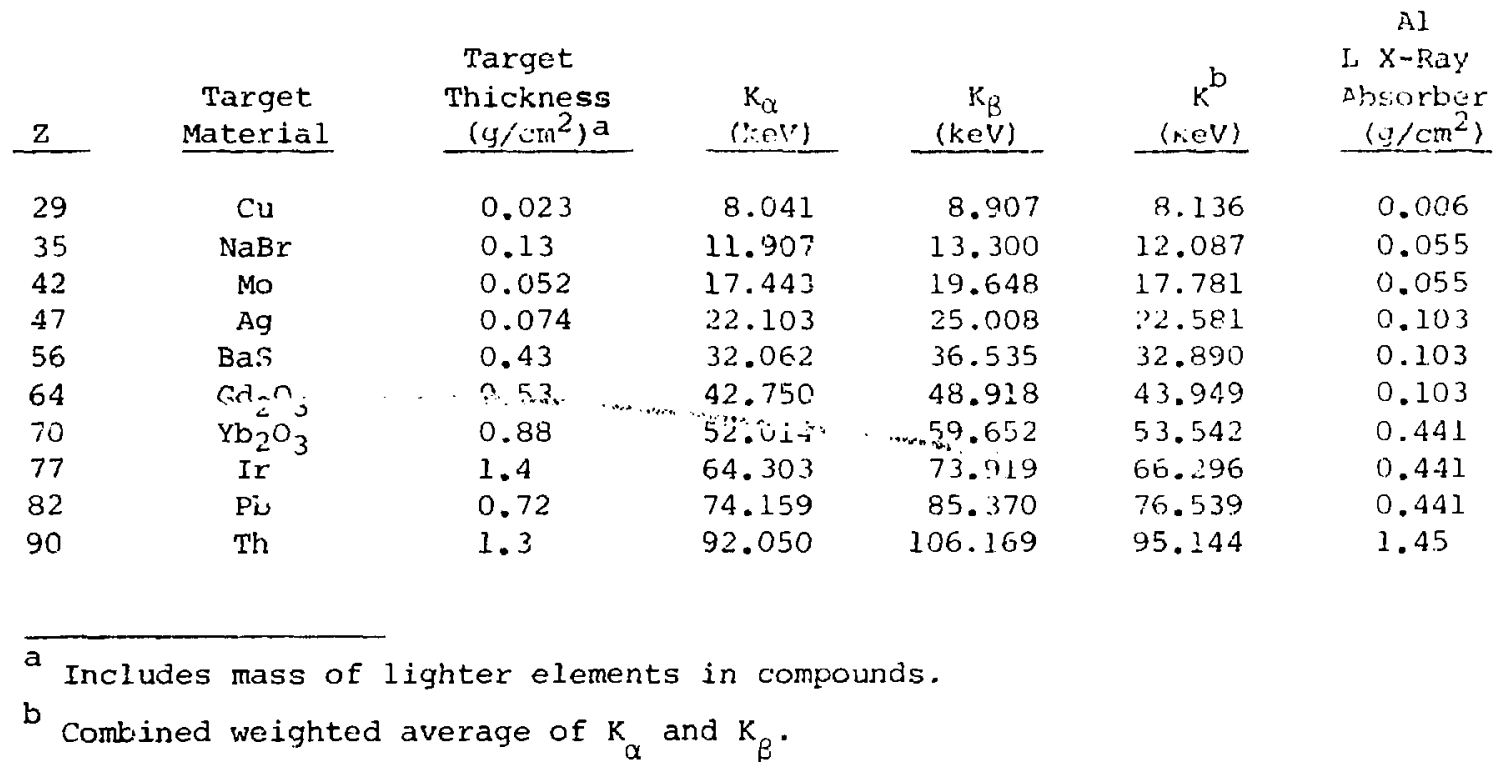

The Technical Mrasurements Corporation (TMC) photon spectroscopy system included a lithium. drifted silicon detector, a cryogenic chamber, an ion pump with power supply, and a $10-\ell$ liquid nitrogen reservoir. The silicon disk was $0.3 \mathrm{~cm}$ thick and 1.27 $\mathrm{cm}$ in diameter with a $0.5-\mu \mathrm{m}$-thick dead layer. A 0.025 -cm-thick beryllium window was mounted in the cryogenic chamber parallel to the plane of the detector so that entering photons were normal to the surface. The first stage of the TMC preamplifier was inside the cryogenic chamber at liquid nitrogen tem. perature, and its output signal was fed to an Ortec model 410 amplifier.

The disk-shaped lithium-drifted germanium detector, Ortec Company model 8047 , was $0.75 \mathrm{~cm}$ thick and $2.28 \mathrm{~cm}$ in diameter with an active area of $4 \mathrm{~cm}^{2}$. It was encapsulated in an aluminum cryostat that rested vertically in a $25-\ell$ Dewar of liquid nitrogen. A $0.046-\mathrm{g} / \mathrm{cm}^{2}$-thick beryllium window in the cryostat was aligned with the side of the detec. tor, i.e., photons were incident on the cylindrical surface of the disk, rather than on one of the plane surfaces. Consequently, the germanium dead layer was $<0.0025 \mathrm{~cm}$. The detector was coupled to an uncooled Los Alamos Scientific Laboratory (LASL) model 580 preamplifier and an Ortec model 410 linear amplifier.

The Harshaw Chemical Company model $12 \mathrm{~S} 12$ detector was a $7.6-\mathrm{cm}$-diam by $7.6-\mathrm{cm}$-deep cylindrical thallium-activated $\mathrm{NaI}$ crystal, optically coupled by a quartz light pipe to an RCA model 8054 photumultiplier tube; the entire unit was crotained in a $0.274-\mathrm{g} / \mathrm{cm}^{2}$-thick aluminum can. Its output signal was fed to a Victoreen lnstrument Company preamplifier model SPA-C and amplifier model SA1.

The detectors were completely shielded except for their windows and rested againsı the detector aper. ture. Alignment was made both optically and by intensity measurements. Background was subtracted with the $x$-ray unit on and with the shutter ove: the fluorescent source.

Pulse height analysis of all spectra was performed with a Victoreen Scipp 400-channel analyzer that was housed with the amplifiers and output equipment in a small trailer near the detector. The 
analyzer gain was set so that one channel vidth corresponded to a $1-\mathrm{keV}$ interval. This setting was ctrecked daily before and after each run, and it wes seldom necessary to adjust the fine gain. Gammaray emitting $i$ : stopes were used to calibrate the spectrometer. These included the $22-\mathrm{keV}{ }^{109} \mathrm{Cd}$ line, the $60-\mathrm{keV}{ }^{241} \mathrm{Am}$ line, the $122 \cdot \mathrm{keV}{ }^{57} \mathrm{Co}$ line, and the $279-\mathrm{keV} 203 \mathrm{Hg}$ line.

Spectral measurements were made with the $x$-ray unit operating at 100,200 , and $300 \mathrm{kV}$. Because the secondary target intensities were considerably srnallet than the primary target intensities, increased tube currents, longer counting times, and larger detector apertures were used to measure the fluorescent spectra. Table II gives tube currents, counting times, and detector aperture areas used with each operating gotential and jetector.

2. Results. Fliorescent spectral measurements are given in Figs, 4-12 in terms of counts per kiloelec. tron volt for the conditions listed in Table II and primary excitation potentials of 100,200 , and 300 ky. Measurement is shown by the actual data points, and theoretical results (described later) are shown by the solid line.

The spectra observed with the silicon detector are shown in Fig. 4 for copper, $\mathrm{NaBr}$, and molybdenum targets. Of the three detectors, silicon had the best resolution but poorest efficiency. ${ }^{16}$ The FWHM resolution was $i$ and $2 \mathrm{kt} V$ at photon energieo of 10 and $100 \mathrm{keV}$, respectively. As a result, the $\mathrm{K}$ lines are relatively narrow. However, the silicon efticiency curve falls rapidly above $20 \mathrm{kgV}$, decreasing to $10 \%$ at $60 \mathrm{keV}$ and to $2 \%$ at $100 \mathrm{keV}$. Thus, the contribution of the scattered spectrum to the total intensity appears to be insignificant.

The thicker and denser germanium detector was considerably more efficient than the silicon detector, and gave truer representation of the importance of the scattered spectrum. The germanium detector's efficiency was essentially 1.0 below $100 \mathrm{keV}$, and fell off rapidly at the higher energies. The germanium measurements are shown in Figs. 548. Resolution of the germanium detector was poorer than that of the silicon detector, being 2- and $3-\mathrm{keV}$ FWHM at photon energies of 10 and $100 \mathrm{keV}$, respectively. The $K_{a}$ and $K_{p}$ lines do not separate until $Z=64$. Escape peaks appear $10 \mathrm{keV}$ below the $K$ lines. As can be seen trom the measurements, the usefulness of the germanium detector was limited to energies $>20$ $\mathrm{keV}$ because of large detector leakage currents.

The Nal detector had the best efficiency, the poorest resolution, and the largest escape peaks of the three detectors (see Figs. 9-12). Resolution of the Nal detector was 4- and 10-keV FWHM at photon energies of 10 and $100 \mathrm{keV}$, respectively. Separation of the $K_{a}$ and $K_{b}$ lines does not occur ever at $Z=$ 90, although the presence of the $K_{\sharp}$ line is apparent

TABLE II

CONDITIONS FOR
FLUORESCENT SPECTRAL MEASUREMENTS

\begin{tabular}{|c|c|c|c|c|c|}
\hline \multirow[b]{2}{*}{$\begin{array}{l}\text { Potential } \\
\quad(\mathrm{kV})\end{array}$} & \multirow[b]{2}{*}{$\begin{array}{l}\text { Current } \\
\text { (mA) }\end{array}$} & \multicolumn{2}{|c|}{$\mathrm{Si}$ and $\mathrm{Ge}$ Detectors ${ }^{\mathrm{a}}$} & \multicolumn{2}{|c|}{ NaI Detector ${ }^{a}$} \\
\hline & & $\begin{array}{r}\text { Area } \\
\left(\mathrm{cm}^{2}\right) \\
\end{array}$ & $\begin{array}{l}\text { Time } \\
\text { (s) }\end{array}$ & $\begin{array}{l}\text { Area } \\
\left(\mathrm{cm}^{2}\right)\end{array}$ & $\begin{array}{r}\text { Time } \\
\text { (s) }\end{array}$ \\
\hline 100 & 15 & 0.114 & 3000 & 2.85 & 600 \\
\hline 200 & 10 & 0.114 & 1800 & 2.85 & 360 \\
\hline 300 & 10 & 0.114 & 1220 & 2.85 & 246 \\
\hline
\end{tabular}

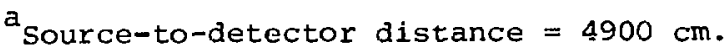




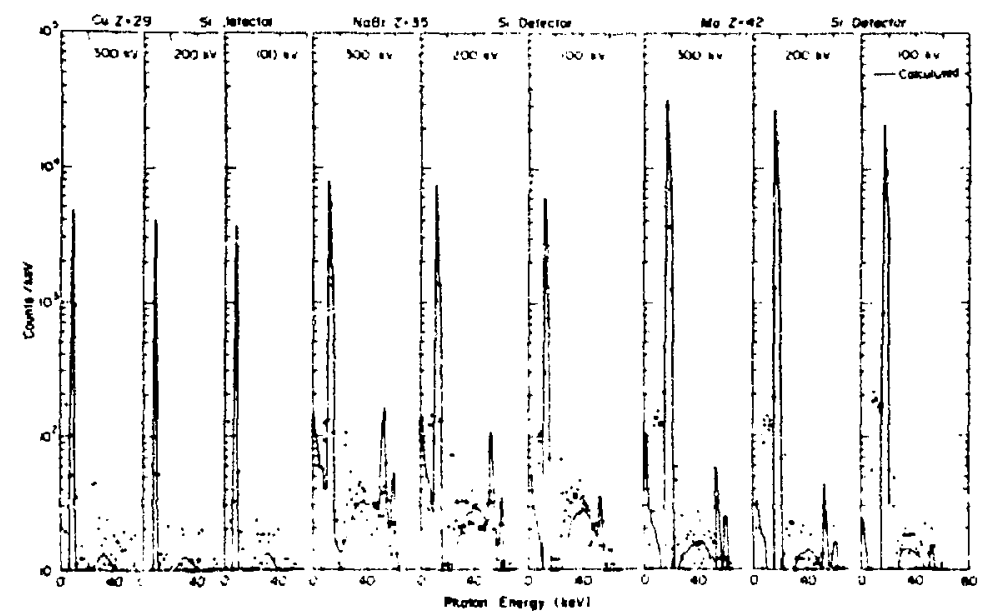

Fig. 4.

Silicon-measured copper, NaBr, and molyüdenum spectra.
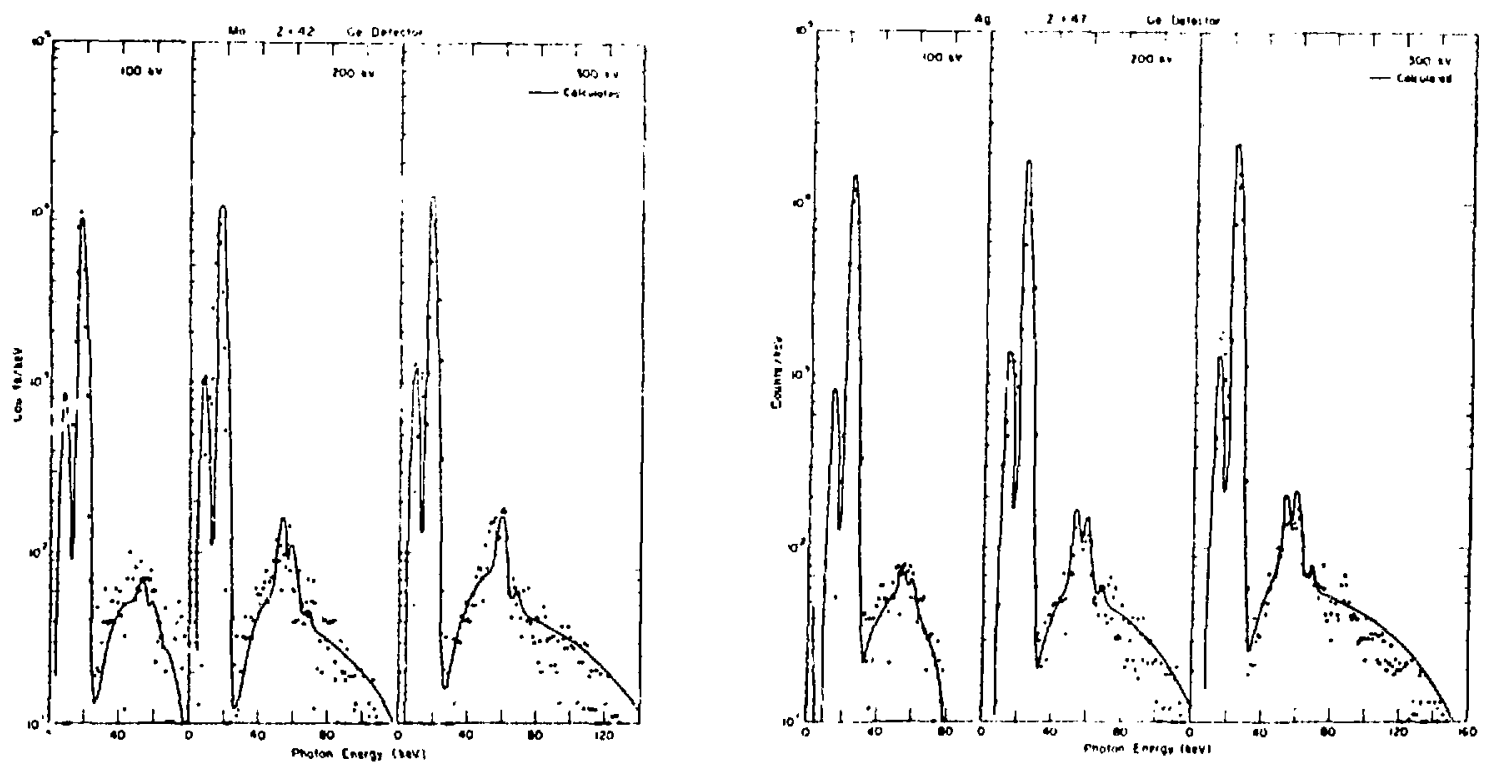

Fig. 5.

Germanium-measured molybdenum and silver spectra. 

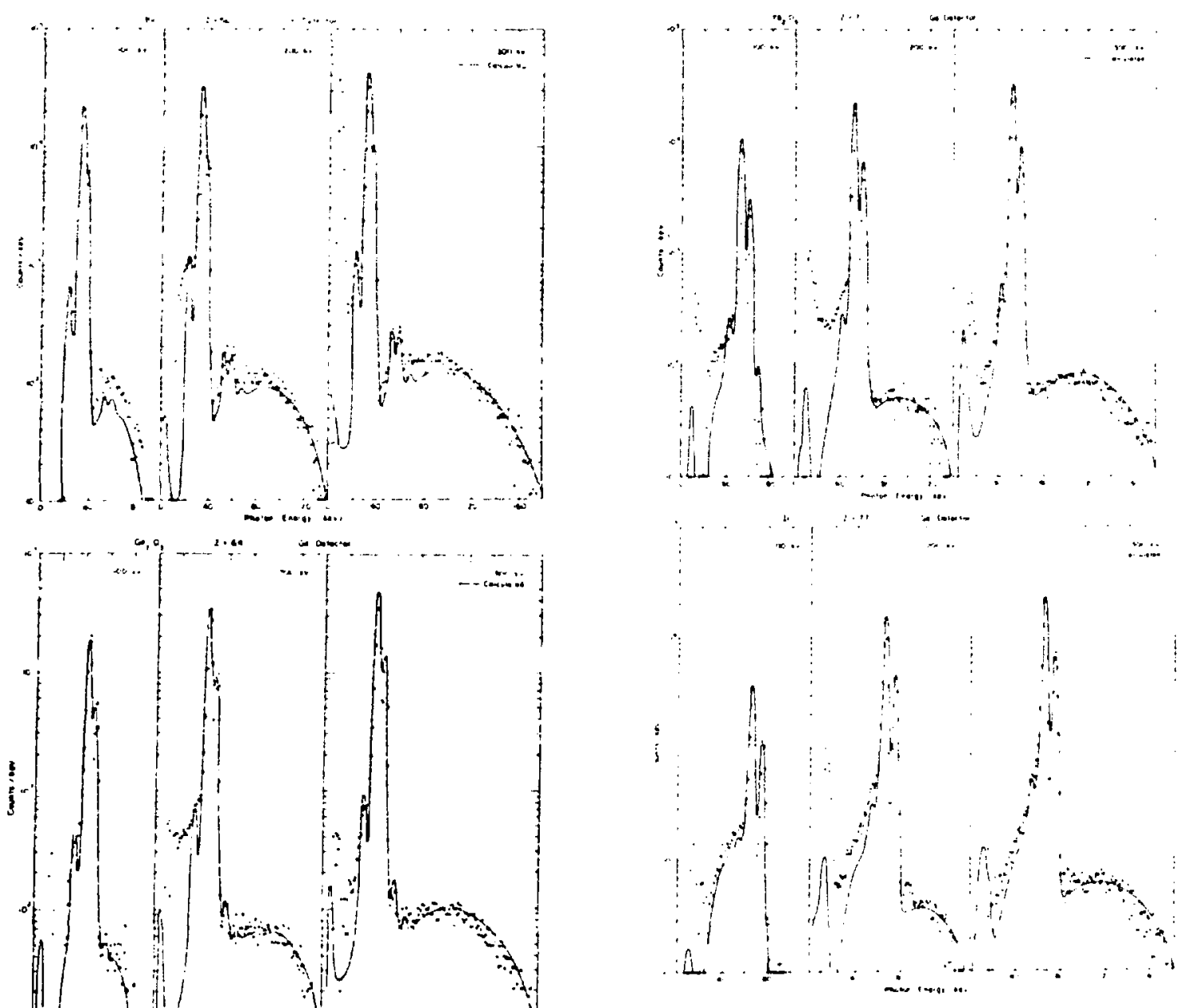

Fig. 6 .

Cirmanium-measured BaS and Gd $C_{\mathrm{s}}$ spectra.

Fig. 7.

Germanium-measured $Y b_{2} O_{3}$ and iridium spectra. 

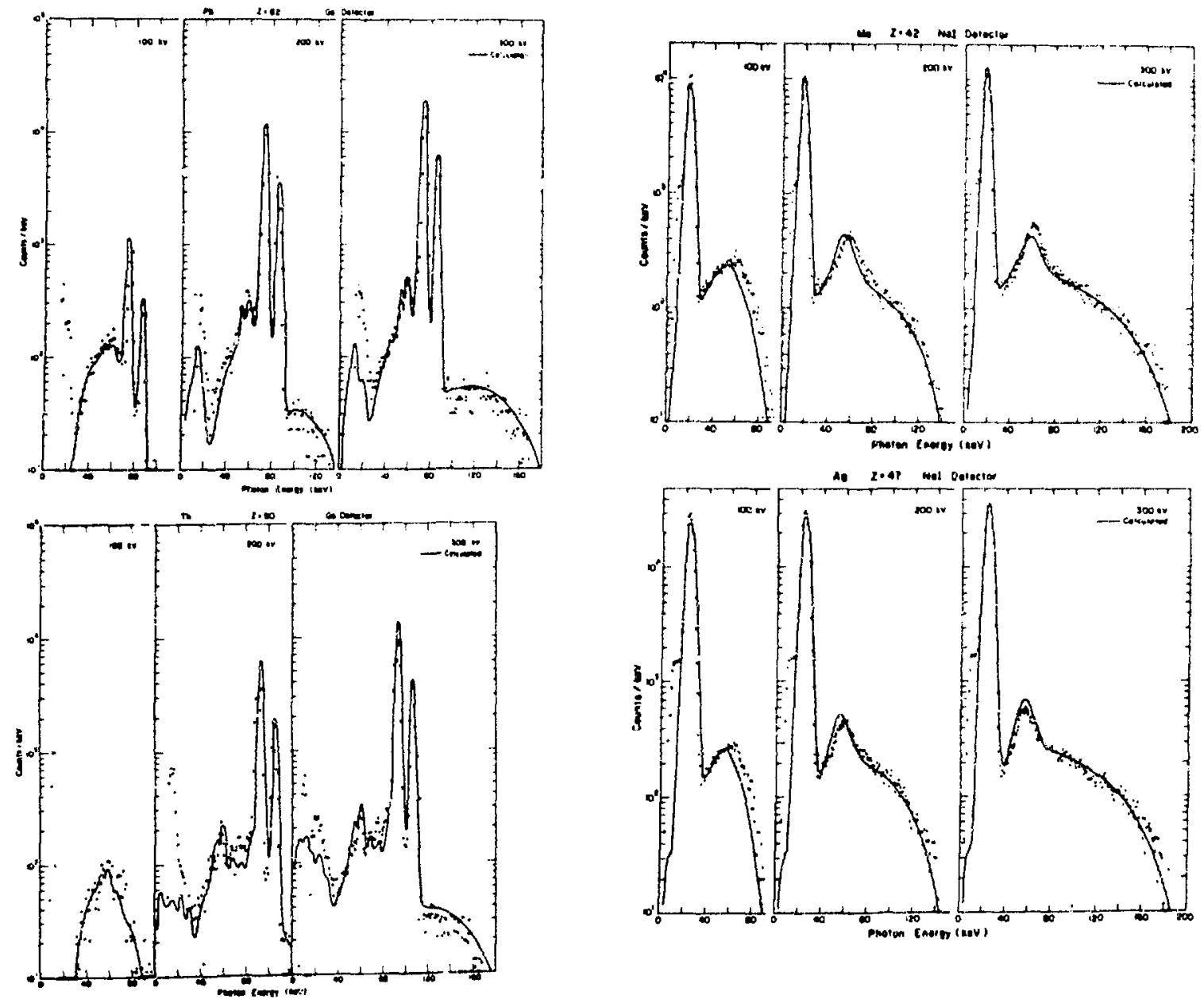

Fig. 8.

Germanium-measured lead and thorium spec-

Fig. 9.

Nal-measured molybdenum and silver spectra. tra. 


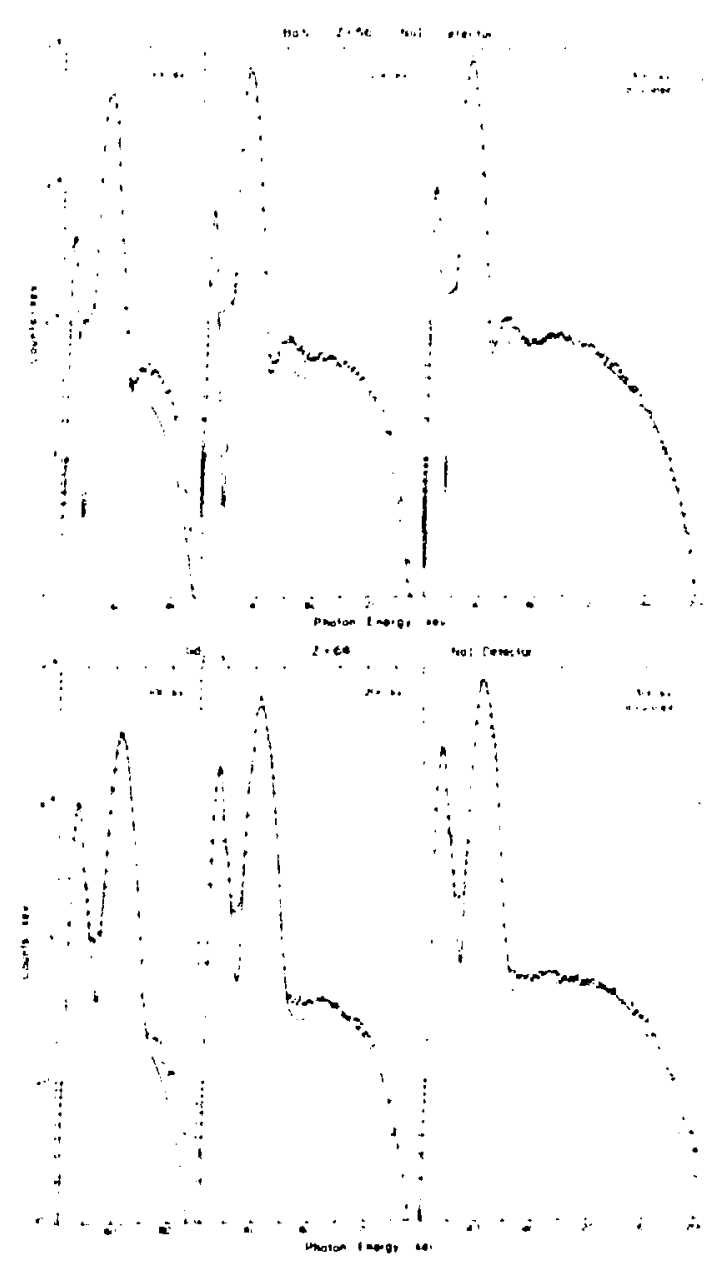

Fig. 10.

Nal-measured Bas and $;$ id 0. spectra.

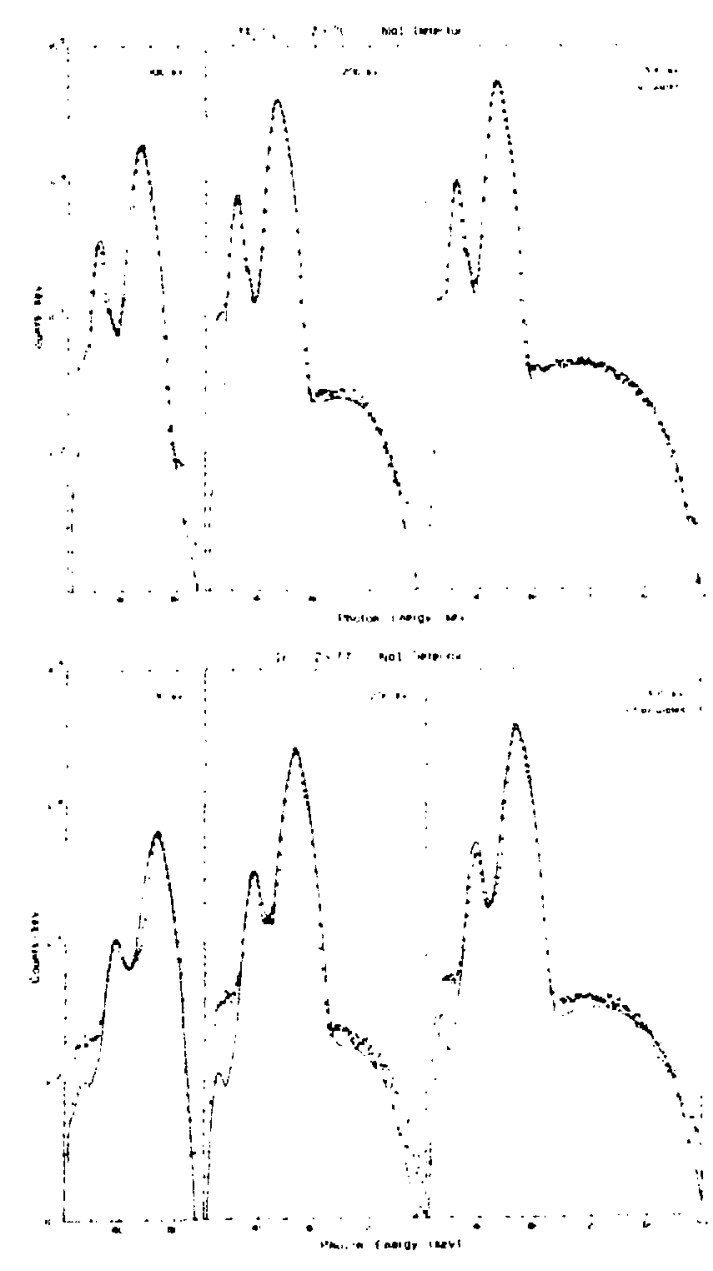

Fig. 11.

Nal-measured $\mathrm{Yb}_{2} \mathrm{O}_{3}$ and iridium spectra. 

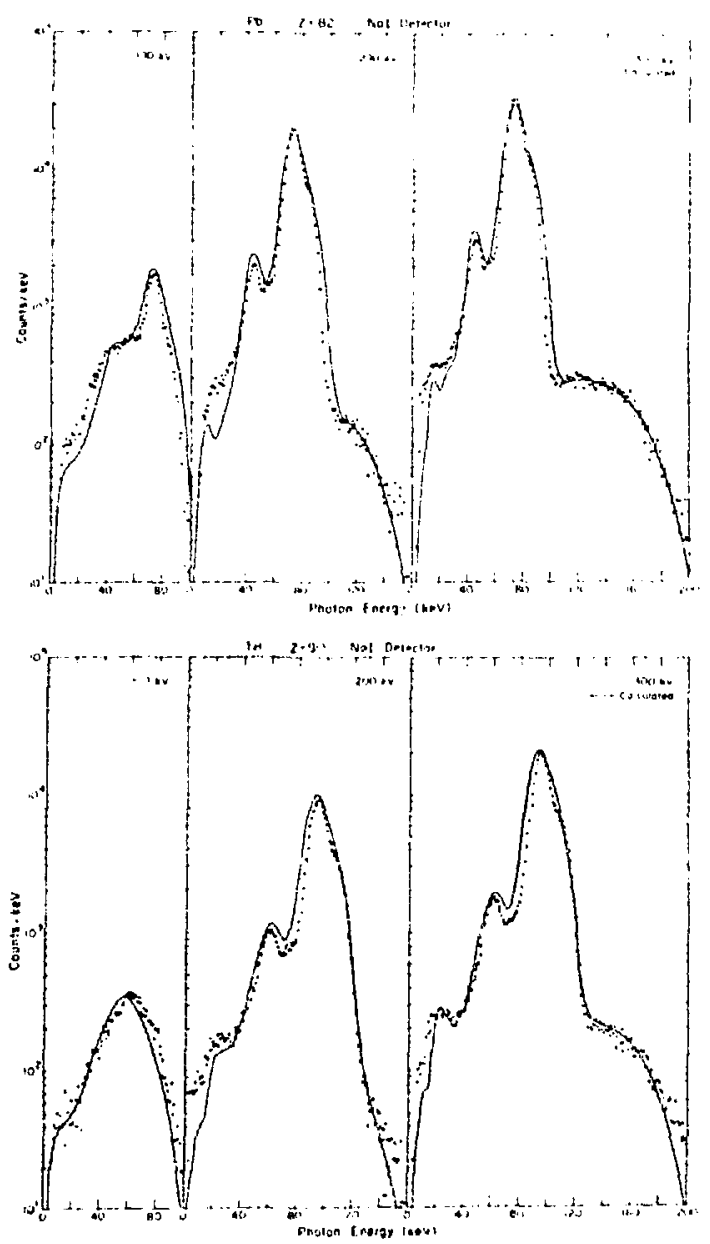

Fig. 12.

Nal-measured lead and thorium sopctra. .

above $Z=56$ from the nonGaussian distribution of the photopeak. Above $Z=56$ the escape peaks also appear $\sim 30 \mathrm{keV}$ below the $\mathrm{K}$ lines. Because the NaI efficiency was 0.9 at $300 \mathrm{keV}$, the $\mathrm{NaI}$ spectra give the clearest representation of the scattered spectrum.

In the spectral measurements shown in Figs. 4-12, the target thicknesses (Table I) were held constant and the primary potential varied. In the spectial measurements, shown in Figs. 13 and 14, the potintial was held constant at $250 \mathrm{kV}$ and the target thicknesses were varied. Spectra obtained with three different thicknesses of copper, molybdenum. gadolinium, and lead foils using the various detectors are shown in Figs. 13 and 14.
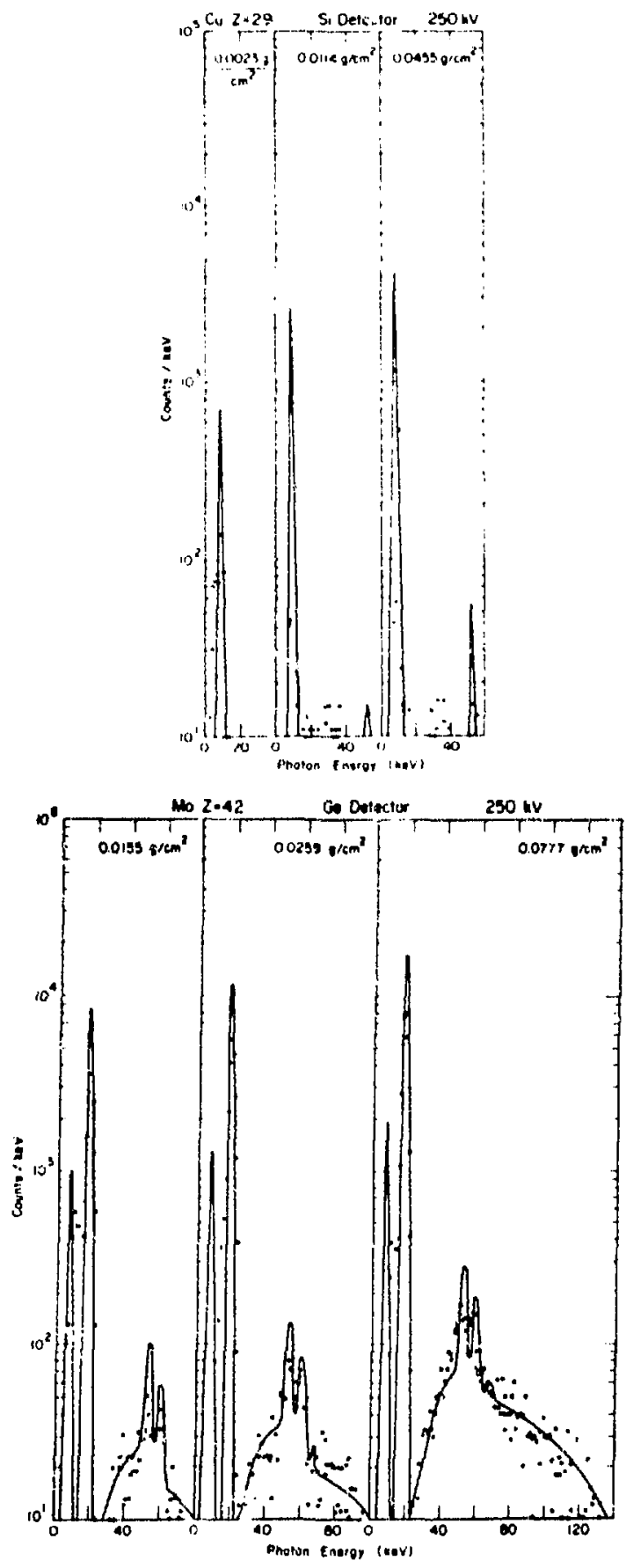

Fig. 13.

Silicon-measured copper and germaniummeasured molybdenum spectra with target thickness voried. 

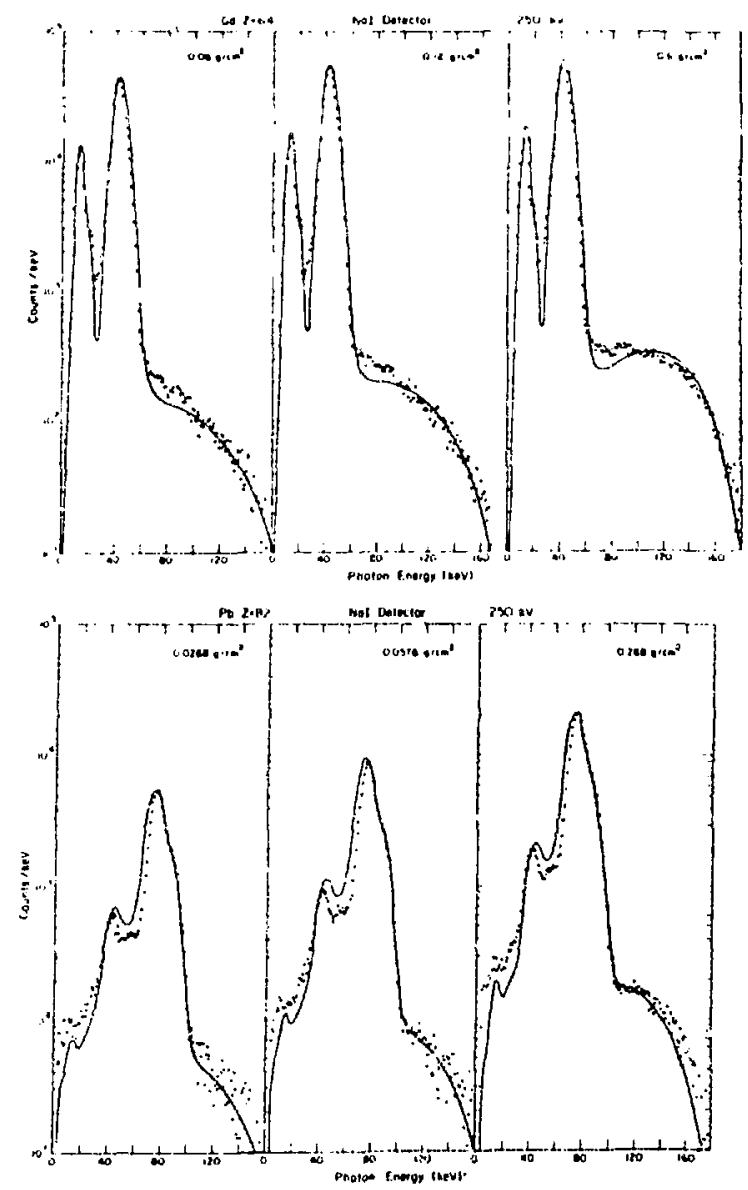

Fig. 14.

Nol-measured gadolinium and lead spectra with target thickness earied.

3. Previous Measurements. There have been many papers ${ }^{1-13}$ describing the use of a primary $x$ ray source to excite fluorescent $\mathrm{K}$ radiation in secondary targets. The geometry used for this report is designed prinarily for use in the calibration of rediation detectors. For example, the equipmant described here has been used to measure the photon energy response of instruments used in personnel dosimetry, health physics surveys, radiation laboratory measurements, x-ray astronomy, and nuclear-device tests. Descriptions of similar calibration facilities at Battelle Memorial Institute, 8,10 Lawrence Livermore Laboratory, ${ }^{6,7}$ and EG\&G J_as Vegas Division " 1 have been reported.
The $200-k \mathrm{~V}$ Rattelle facility was first discribed by Larson et al. ${ }^{10}$ without spectral measurements, but later Kathren et al. ${ }^{B}$ presented fluorescent spectral measurements for six metallic targets with atomic numbers from 40 to 92 and primary voltages of 60 to $140 \mathrm{kV}$. The measurements were in terms of relative intensity and indicated more low-energy scatter than was found in the present measurements, probably because of the much thinner inherent filt ration in Battelle's primary $x$-ray tube.

Livermore used three separate $x$-ray units with maximum operating potentials of 75,150 , and 400 $\mathrm{kV}$ to obtain fluorescent $x$ rays from 22 targets varying in atomic number from 29 to 92 . Gaines et 81.6 presented a catalog of fluorescent spectral measurements with and without prefilters (which reduce low-energy scatter) and postfilters 'which preferentially attenuate $K_{\beta}$ lines to obtei urer $K_{\alpha}$ lines). The spectra were presented in figures without numerical values for either intensity or photon energy.

The EG\&G reports ${ }^{11}$ described a $75 \cdot \mathrm{kV}$ x-ray unit used to obtain fluorescent $\mathrm{x}$ rays. Spectral measurements were given for 11 targets in terms of relative intensity. The measurements made by Battelle and EG\&G indicated more low-energy scatter than the present measurements because of thinner inherent filtration.

In effect, there do not appear to be any measurements that can be directly compared with the secondary-target spectral measurements given here. In addition, no attempt seems to have been made to predict the secondary target spectra theoretically.

\section{Theory}

\section{A. Geometry Assumed in the Calculation.}

The geometry of the experimental arrangement is shown in Fix. 15. Photons from the primary target pass through the beam-limiting aperture and strike the secondary target, which is inclined at a $45^{\circ}$ angle to the central ray of the primary beam. Distances from the primary target to the beam-limiting aperture and to the renter of the secondary target are $r_{t}$ and $r_{r}$, respectively. The area of the beam-limiting diaphragm and the area of the secondary target irradiated by the primary beam are $A_{t}$ and $A_{r}$, respectively. 

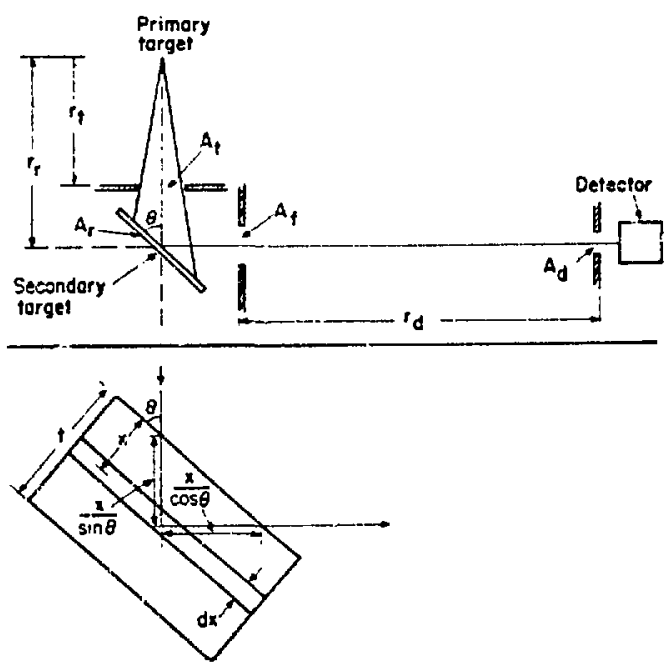

Fig. 15.

Geometry used in speciral measurements.

Because each point on the secondary target is not the same distance from the primary target, the target is irradiated nonuniformly. At the secondary target position, the irradiated area is elliptical. Along the major axis, the point closest to the primary target is the most intense and the point farthest is the least intense. However, because the most intense point is farthest and the least intense point closest to the fluorescent diaphragm of area $A_{i}$, the intensity is essentially uniform at the diaphragm when the target is oriented $45^{\circ}$ with respect to the primary beam. In effect, the geometry results in a uniform 2.2-cm-diam circular source located at the fluorescent diaphragm.

Films placed at various distances from the fluores cent diaphragm showed that the intensity was uniform over a circular region and fell off gradually at the edges. The diameter $d_{f}$ of the central uniform region was proportional to source-to-detictor distance $r_{d}$ and was given by $d_{f}=0.08 r_{d}$ for $r_{d}>15 \mathrm{~cm}$. Ionization chamber measurements demonstrated that for distances $>15 \mathrm{~cm}$, the inverse square law was obeyed within $2 \%$ if distances were measured from the fluorescent diaphragm to the detector.

Referring once more to Fig. 15, the primary beam produces $\mathrm{K}$-fluorescent radiation in the secondary target, and scatters both incoherently and coherently from the target. The $K$ and scattered photons pass through the fluorescent diaphragm, area $\mathbf{A}_{f}$, and are measured by the detritor with aperture srea $A_{i}$, located a distance $r_{i j}$ from the fluorescent diaphragm. 'The photons ennitted from the target are observed at a $90^{\circ}$ angle to the central ray of the primary beam.

\section{B. Primary Iniensity Inside the Target}

As mentioned earlier, the undistorted "measured" spectra shown in Fig. 1. which irclude inherent filtration, will be assumed in the following calculation to represent the primary spestral distributions, referred to as $I_{\text {primary }}$ and given in units of photuns/s$\mathrm{mA}-\mathrm{keV}$-sr.

From Fig. 15, the solid angle subiended by the secondary target is $A_{t} / r_{1}{ }^{2}$. The total target area irradiated at distance $r_{r}$ is $A_{r}=\left(A_{t} / \sin \theta\right)\left(r_{1} 2 / r_{1}{ }^{2}\right)$. Hence, the photon intensity $p \in r$ unit area incident on the target is

$$
\begin{aligned}
i_{\text {incident }} & =I_{\text {primaiy }}\left[\begin{array}{l}
\Lambda_{t} \\
\frac{r_{t}^{2}}{2}
\end{array}\right]\left[\frac{\sin \theta}{\lambda_{t}} \frac{r_{t}^{2}}{r_{r}^{2}}\right] \\
& =I_{\text {primary }} \frac{\operatorname{sirt} \theta}{r_{r}^{2}}
\end{aligned}
$$

where $\mathrm{I}_{\text {inciden }}$ is in units of photuns/s-mA-keV-cm².

The intensity of the incident team at a point $x$ in the target is

$$
I_{x}=I_{\text {incident }} \exp \left\{-\mu_{k} x / \sin \theta\right\} \text {, }
$$

where $\mu_{k}$ is the total attenuation coefficient of the incident photons with energy $k$, and $x / \sin \theta$ is the distance traveled by the photons inside the target to reach point $x$.

The decrease in incident beam intensity in passing through an infinitesimal layer $d x$ is, by differen. tiating Eq. (2), 


$$
\begin{gathered}
d I_{x}=-I_{\text {incident }}\left(\mu_{k} x / \sin \theta\right) \\
x \exp \left\{-\mu_{k} x / \sin \theta\right\} d x .
\end{gathered}
$$

If $\mathrm{dl}_{\text {interaltion }}=-\mathrm{dl}_{\mathrm{x}}$ is the intensity of the photons interacting in the layer $d x$, then from $\mathrm{Eq}$. (1) the interaction intersity in terms of $I_{\text {primary }}$ is

$$
\begin{gathered}
\left.\mathrm{dI}_{\text {interaction }}=I_{\text {printary }} / \mathrm{r}_{\mathrm{r}}^{2}\right) \mu_{\mathrm{k}} \\
x \exp \left\{\sim \mu_{\mathrm{k}} \mathrm{x} / \sin \theta\right\} \mathrm{d} x .
\end{gathered}
$$

In the energy region of iitterest, $10 \leq k \leq 300 \mathrm{keV}$, the total attenuation coefficient is the sum of the photoelectric $\left(\tau_{k}\right)$, coherent $\left(\sigma_{\text {coh }}\right)$, and incoherent $\left(\sigma_{\text {inc }}\right)$ coefficients, i.e..

$$
\mu_{k}: \tau_{k}+\sigma_{\text {coh }}+\sigma_{\text {inc }} .
$$

Hence, the ploton interaction intensity can be written as the sum of three terms.

$$
\begin{aligned}
& \mathrm{dI}_{\text {interaction }}=\left(1_{\text {primary }} / \mathrm{r}_{\mathrm{r}}{ }^{2}\right) \\
& \times \int \tau_{\mathrm{k}} \exp \left\{-\mu_{\mathrm{k}} \mathrm{x} / \sin \theta\right\} \\
& +\sigma_{\operatorname{coh}} \exp \left\{-\mu_{\mathrm{k}} \mathrm{x} / \sin \theta\right\} \\
& \left.+\sigma_{\text {inc }} \exp \left\{-\mu_{\mathrm{k}} \mathrm{x}^{\prime} \sin \theta\right\}\right] \mathrm{dx} .
\end{aligned}
$$

\section{K Photons}

$K_{a}$ - and $K_{\beta}$-photon intensities can be calculated from the first term in Eq. (6). The photoelectric coefficient, $\tau_{k}$, represents the probability of a photon interaction occurring in any of the atomic shells. If $\sigma_{\mathrm{K}} / \sigma_{\mathrm{T}}$ is the ratio of $\mathrm{K}$ shell to total shell interac. tions, then $\left(\tau_{k}\right)\left(\sigma_{K} / \sigma_{T}\right)$ is the probability of a photon interacting only with atonic $K$ shells. Of the photous interacting with atomic ir shells, only a fraction produce $K_{\alpha}$ photons. If $\omega_{K}$ is the rativ of $K$ photons produced to $\mathrm{K}$-shell interactions and $\mathrm{K}_{\alpha} / \mathrm{K}_{\mathrm{r}}$ is the ratio of $K_{a}$ to total $K$ photons produced, then the probability of photons with energy $k$ proc scing $K_{\alpha}$ photon; is $\left(7_{k}\right)\left(\sigma_{K} / \sigma_{T}\right)\left(\omega_{K}\right)\left(K_{\alpha} / K_{T}\right)$.

From the layer $\mathrm{dx}, K_{a}$ photons travel a distance $x / \cos \theta$ before laaving the target. Hexice, they are attenuated by a factor $\exp \left[-\mu_{K_{x}} \mathrm{x} / \cos \theta\right]$, where $\mu_{K_{\alpha}}$ is the iotal attenuation coefficient of a photons with energy $K_{a}$.

Only the fraction of the photorus leaving the taiget and directed toward the detector are recorded. Because the $K_{\alpha}$ photons are emitted isotropically, only $1 / 4$ ir reach the detertor. The area seen by the detector is $A_{f} / \sin 6$, where $A_{f}$ is the area of the Tuorescent diaphragm.

Thus the $K_{\alpha}$-photon intensity leaving the target in the direction of the detector from the layer $d x$ is

$$
\begin{aligned}
& \mathrm{dI}_{K_{U}}=\left(I_{\text {primary }} / \mathrm{r}_{\mathrm{r}}^{2}\right)\left(A_{f} / \sin \theta\right) \\
& x \quad(1 / 4 \pi)\left[\frac{\alpha^{\alpha}}{K_{T}} \omega_{K} \frac{\sigma_{K}}{\sigma_{T}}\right]{ }^{T_{k}} \\
& x \exp \left\{-\mu_{k} x / \sin \theta-\mu_{K_{\alpha}} x / \cos \theta\right\} \\
& x \mathrm{dx} \text {. }
\end{aligned}
$$

Integration over the total thickness $t$ of the target with $\theta=45^{\circ}$ gives 


$$
\begin{aligned}
I_{K_{\alpha}} & =I_{\text {primary }}\left(A_{f} / r_{r}^{2}\right) \\
x & {\left[\frac{K_{\alpha}}{K_{T}} \frac{\omega_{K}}{4 \pi} \frac{\sigma_{K}}{\sigma_{T}}\right] \frac{\tau_{k}}{\mu_{k}+\mu_{K}} } \\
x & {\left[1-\exp \left\{-\sqrt{2}\left(\mu_{k}+\mu_{K}\right) t\right\}\right] . }
\end{aligned}
$$

However, $K_{a}$ photons are produced only by photons in the incident spectrum with energies between $k_{k}$, the $K$-edge energy, and $k_{0}=T_{0}$, the maximum photon energy or the accelerating potential of the primary $x$-ray tube. Thus, the $K_{\alpha}$-phnton intensity produced by photons with energy $k_{K} \leq k \leq k_{n}$ and emitted from ths target is

$$
\begin{aligned}
I_{K_{\alpha}} & =\left[\frac{K_{\alpha}}{K_{T}} \frac{\omega_{K}}{4 \pi} \frac{\sigma_{K}}{\sigma_{T}}\right]\left(A_{\mathrm{f}} / \mathrm{r}_{\mathrm{r}}^{2}\right) \\
& \times \int_{\mathrm{k}_{\mathrm{K}}}^{k_{\mathrm{c}}} \mathrm{I}_{\text {primary }} \frac{{ }^{\tau} \mathrm{k}}{\mu_{\mathrm{k}}+\mu_{\mathrm{K}}} \\
& \times\left[1-\exp \left\{-\sqrt{2}\left(\mu_{\mathrm{k}}+\mu_{\mathrm{K}}\right) \mathrm{t}\right\}\right] \\
& \times[\mathrm{dk} .
\end{aligned}
$$

Similarly the $K_{\beta}$-photon intensity emitted from the target is

$$
\begin{aligned}
I_{K_{B}} & \left.=\left[\frac{K_{B}}{K_{T}} \frac{\omega_{K}}{4 \pi} \frac{\sigma_{K}}{\sigma_{T}}\right] I_{f} / r_{r}^{2}\right) \\
& x \int_{k_{K}}^{k_{0}} I_{p r i m a r y} \frac{\tau_{k}}{\mu_{k}+\mu_{K}} \\
x & {\left[1-\exp \left\{-\sqrt{2}\left(\mu_{k}+\mu_{K} ; t\right\}\right]\right.} \\
x & \text { dk. }
\end{aligned}
$$

where $I_{K_{\alpha}}$ and $I_{K_{\beta}}$ are in units of photons/s-mA-sr.

The numerical values used in this calculation for $\omega_{K}, \sigma_{K} / \sigma_{\mathrm{T}}, K_{\alpha} / K_{\mathrm{T}}, K_{\beta} / K_{\mathrm{T}}, \mu_{\mathrm{K} \alpha}$, and $\mu_{\mathrm{K}_{\beta}}$ are listed in Table III. Photoelectric $\tau_{k}$ and total $\mu_{k}$ attenuation coefficients are given in Tables IV and $V$, respectively. The fluorescent diaphragm area $A_{f}$ was 3.80 $\mathrm{cm}^{2}$ and the primary to secondary target distance $r_{r}$ was $15 \mathrm{~cm}$.

\section{Coherently Scattered Photons}

The coherently scattered photon intensity can be calculated from the second term in Eq. (6). The coherent scattering coefficient $\sigma_{\mathrm{coh}}$ represents the probability of a coherent interaction occurring, sum. med over all angles of photon emission. Figure 15 shows that only photons leaving the secondary target at a $90^{\circ}$ angle to the incident beam are recorded by the detector. Therefore, $\sigma_{c o h}$ must be replaced by $\mathrm{d} \sigma_{\mathrm{col}} / \mathrm{d} \Omega$, which represents the probability that a photon with energy $k$ will interact coherently in the layer $d x$ and a scattered photon will emerge in the direction of the detector within the solid angle $d \Omega$.

In Rayleigh or coherent scatter, a photon with energy $k$ interacts with atomic electrons and is reradiated with the same energy $k$. Coherently scattered photons, produced in the layer $\mathrm{dx}$, travel a distance $x / \cos \theta$ in reaching the surface of the target and are attenuated by a factor $\exp \left[-\mu_{\mathrm{k}} \mathrm{x} / \cos \theta\right]$. Thus the coherently scattered photon intensity leaving the target in the direction of the detector from layer $\mathrm{dx}$ is 
TABIE III

CONSTANTS USED IN THE CALCULATION

OF SECONDARY TARGET RADIATION

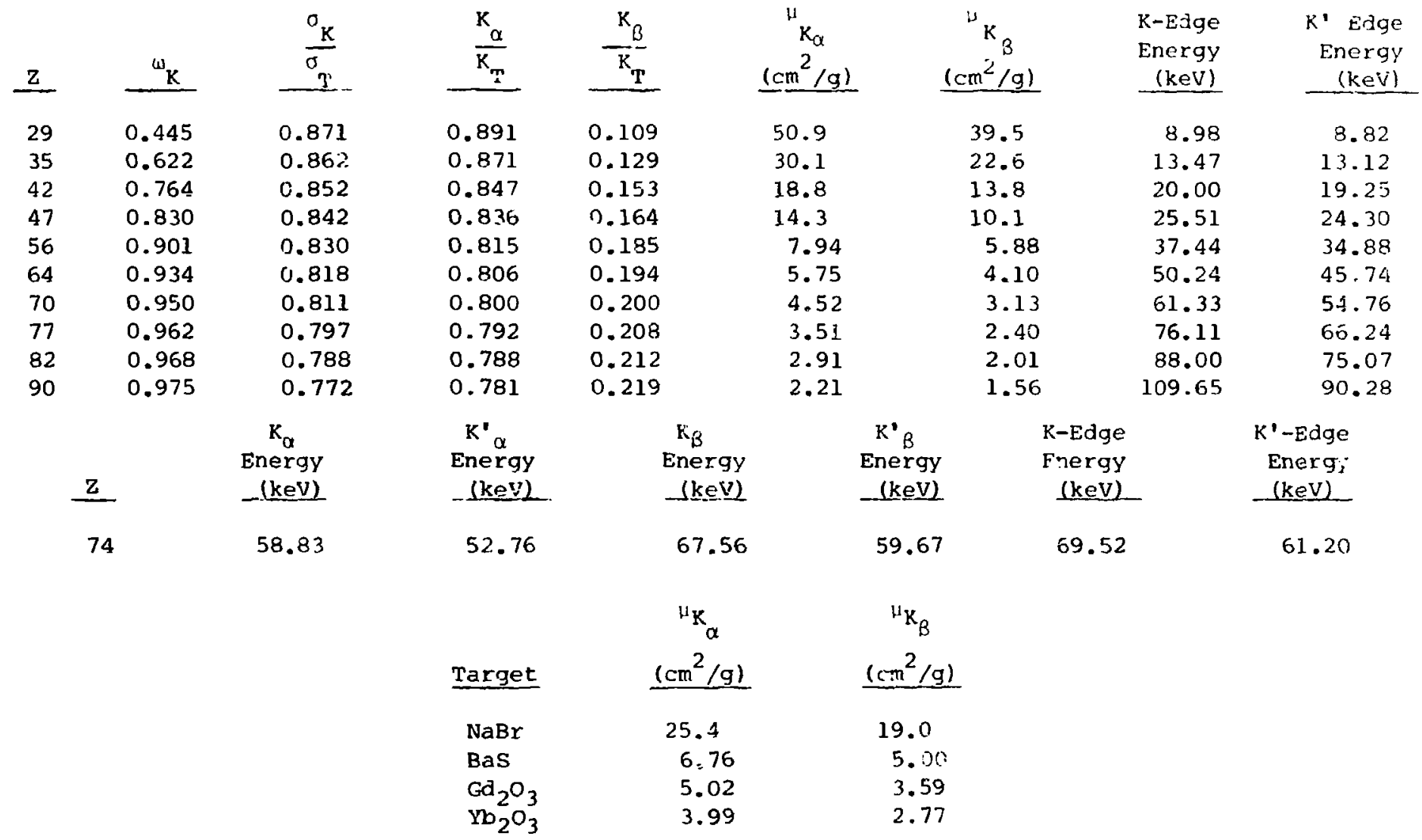


TABLE IV

SECONDARY TARGET PHOFOELECTRIC COEFFICIENTS ( ${ }_{k}$ )

\begin{tabular}{|c|c|c|c|c|c|c|c|}
\hline $\begin{array}{r}k \\
(\mathrm{keV}) \\
\end{array}$ & $\begin{array}{c}\mathrm{Cu} \\
\left(\mathrm{cm}^{2} / \mathrm{g}\right) \\
\end{array}$ & $\begin{array}{c}\mathrm{Br} \\
\left(\mathrm{cm}^{2} / \mathrm{g}\right) \\
\end{array}$ & $\begin{array}{c}\text { Mo } \\
\left(\mathrm{cm}^{2} / \mathrm{g}\right) \\
\end{array}$ & $\begin{array}{c}n g \\
\left(\mathrm{~cm}^{2} / g\right) \\
\end{array}$ & $\begin{array}{r}\mathrm{Ba} \\
\left(\mathrm{cm}^{2} / \mathrm{g}\right) \\
\end{array}$ & $\begin{array}{c}\mathrm{Gd} \\
\left(\mathrm{cm}^{2} / \mathrm{g}\right) \\
\end{array}$ & $\begin{array}{r}\mathrm{Yb} \\
\left(\mathrm{cm}^{2} / \mathrm{g}\right) \\
\end{array}$ \\
\hline 8.98 & 283 & & & & & & \\
\hline 13.47 & & 148 & & & & & \\
\hline 20.00 & 33.0 & 51.6 & 81.0 & & & & \\
\hline 25.51 & & & & 55.0 & & & \\
\hline 30 & 10.3 & 16.9 & 27.3 & 35.8 & & & \\
\hline 37.44 & & & & & 28.5 & & \\
\hline 40 & 4.48 & 7.54 & 12.4 & 1.6 .6 & 23.9 & & \\
\hline 50 & 2.31 & 3.96 & 6.59 & 8.99 & 13.2 & & \\
\hline 50.24 & & & & & & 18.0 & \\
\hline 60 & 1.35 & 2.33 & 3.94 & 5.40 & 8.11 & 11.3 & \\
\hline 61.33 & & & & & & & 13.1 \\
\hline $\begin{array}{l}70 \\
76.11\end{array}$ & 0.853 & 3. .51 & 2.54 & 3.52 & 5.44 & 7.66 & 9.22 \\
\hline $\begin{array}{l}80 \\
88.00\end{array}$ & 0.561 & 0.995 & 1.71 & 2.39 & 3.67 & 5.25 & 6.54 \\
\hline 90 & 0.393 & 0.701 & 1.19 & 3.69 & 2.65 & 3.79 & 4.73 \\
\hline 100 & 0.284 & 0.509 & 0.891 & 1. . 25 & 1.96 & 2.84 & 3.58 \\
\hline 109.65 & & & & & & & \\
\hline 110 & 0.211 & 0.381 & 0.672 & 0.949 & 1.50 & 2.19 & 2.78 \\
\hline 120 & 0.163 & 0.292 & 0.515 & 0.731 & 1.16 & 1.72 & 2.18 \\
\hline 130 & 0.128 & 0.226 & 0.408 & 0.586 & 0.934 & 1.38 & 1.75 \\
\hline 140 & 0.102 & 0.181 & 0.330 & 0.475 & 0.750 & 1.12 & 1.43 \\
\hline 150 & 0.0826 & 0.148 & 0.272 & 0.3837 & 0.627 & 0.938 & 1.20 \\
\hline 160 & 0.0682 & 0.122 & 0.222 & 0.321 & 0.522 & 0.777 & 0.985 \\
\hline 70 & 0.0569 & 0.103 & 0.187 & 0.270 & 0.439 & 0.659 & 0.849 \\
\hline 180 & 0.0479 & 0.0867 & 0.158 & 0.229 & 0.384 & 0.555 & 0.731 \\
\hline 190 & 0.0408 & 0.0739 & 0.135 & 0.195 & 0.320 & 0.479 & 0.626 \\
\hline 200 & 0.0345 & 0.0637 & 0.117 & 0.168 & 0.276 & 0.406 & 0.546 \\
\hline 210 & 0.0303 & 0.0550 & 0.100 & 0.147 & 0.244 & 0.364 & 0.477 \\
\hline 220 & 0.0263 & 0.0482 & 0.0879 & 0.128 & 0.213 & 0.320 & 0.421 \\
\hline 230 & 0.0229 & 0.0421 & 0.0766 & 0.113 & 0.189 & 0.283 & 0.376 \\
\hline 240 & 0.0203 & 0.0372 & 0.0684 & 0.0999 & 0.168 & 0.253 & 0.338 \\
\hline 250 & 0.0179 & 0.0329 & 0.0603 & 0.0877 & 0.150 & 0.228 & 0.301 \\
\hline 260 & 0.0160 & 0.0294 & 0.0540 & 0.0787 & 0.135 & 0.205 & 0.271 \\
\hline 270 & 0.0143 & 0.0264 & 0.0486 & 0.0703 & 0.12 .1 & 0.186 & 0.245 \\
\hline 280 & 0.0128 & 0.0237 & 0.0439 & 0.0636 & 0.110 & 0.169 & 0.223 \\
\hline 90 & 0.0117 & 0.0216 & 0.0395 & 0.0575 & 0.0995 & 0.153 & 0.204 \\
\hline
\end{tabular}


TABLE IV (cont)

\begin{tabular}{|c|c|c|c|c|c|c|c|}
\hline $\begin{array}{c}k \\
(\mathrm{kev})\end{array}$ & $\begin{array}{c}\text { Ir } \\
\left(\Delta m^{2} / g\right) \\
\end{array}$ & $\begin{array}{c}P i \\
2 \\
\left(\mathrm{~cm}^{2} / \mathrm{g}\right) \\
\end{array}$ & $\begin{array}{c}\text { Th } \\
\left(\mathrm{cm}^{2} / \mathrm{g}\right) \\
\end{array}$ & $\begin{array}{c}\mathrm{NaBr} \\
\left(\mathrm{cm}^{2} / \mathrm{g}\right) \\
\end{array}$ & $\begin{array}{c}\mathrm{Bas} \\
\left(\mathrm{cm}^{2} / \mathrm{g}\right) \\
\end{array}$ & $\begin{array}{r}\mathrm{Gd}_{2} \mathrm{O}_{3} \\
\left(\mathrm{~cm}^{2} / \mathrm{g}\right)\end{array}$ & $\begin{array}{l}\mathrm{Yb}_{2} \mathrm{O}_{3} \\
\left(\mathrm{~cm}^{2} / \mathrm{g}\right) \\
\end{array}$ \\
\hline 8.98 & & & & & & & \\
\hline 13.47 & & & & 116 & & & \\
\hline 20.00 & & & & 40.5 & & & \\
\hline 25.51 & & & & & & & \\
\hline 30 & & & & 13.2 & & & \\
\hline 37.44 & & & & & 23.3 & & \\
\hline 40 & & & & 5.90 & 19.5 & & \\
\hline 50 & & & & 3.10 & 10.8 & & \\
\hline 50.24 & & & & & & 15.6 & \\
\hline 60 & & & & 1.82 & 6.61 & 9.81 & \\
\hline 61.33 & & & & & & & 11.5 \\
\hline 70 & & & & 1.18 & 4.54 & 6.65 & 8.10 \\
\hline 76.11 & 9.21 & & & & & & \\
\hline 80 & 8.11 & & & 0.777 & 2.99 & 4.56 & 5.74 \\
\hline 88.00 & & 7.21 & & & & & \\
\hline 90 & 5.98 & 6.83 & & 0.547 & 2.16 & 3.29 & 4.15 \\
\hline 100 & 4.54 & 5.23 & & 0.397 & 1.60 & 2.46 & 3.14 \\
\hline 109.65 & & & 4.98 & & & & \\
\hline 110 & 3.54 & 4.07 & & 0.297 & 1.22 & 1.90 & 2.44 \\
\hline 120 & 2.79 & 3.23 & 4.02 & 0.228 & 0.945 & 1.49 & 1.91 \\
\hline 130 & 2.26 & 2.62 & 3.27 & 0.176 & 0.760 & 1.20 & 1.54 \\
\hline 140 & 1.86 & 2.17 & 2.70 & 0.141 & 0.611 & 0.972 & 1.26 \\
\hline 150 & 1.56 & 1.82 & 2.27 & 0.116 & 0.510 & 0.814 & 1.05 \\
\hline 160 & 1.32 & 1.53 & 1.92 & 0.0952 & 0.425 & 0.674 & 0.865 \\
\hline 170 & 1.12 & 1.30 & 1.63 & 0.0804 & 0.357 & 0.572 & 0.746 \\
\hline 180 & 0.959 & 1.12 & 1.41 & 0.0677 & 0.312 & 0.482 & 0.642 \\
\hline 190 & 0.827 & 0.965 & 1.23 & 0.0577 & 0.260 & 0.416 & 0.550 \\
\hline 200 & 0.717 & 0.849 & 1.07 & 0.0497 & 0.225 & 0.362 & 0.480 \\
\hline 210 & 0.636 & 0.744 & 0.942 & 0.0429 & 0.198 & 0.316 & 0.419 \\
\hline 220 & 0.564 & 0.660 & 0.838 & 0.0376 & 0.173 & 0.278 & 0.370 \\
\hline 230 & 0.501 & 0.590 & 0.747 & 0.0328 & 0.154 & 0.246 & 0.330 \\
\hline 240 & 0.442 & 0.523 & 0.667 & 0.0290 & 0.137 & 0.220 & 0.297 \\
\hline 250 & 0.401 & 0.474 & 0.602 & 0.0257 & 0.122 & 0.198 & 0.264 \\
\hline 260 & 0.357 & 0.427 & 0.545 & 0.0229 & 0.110 & 0.178 & 0.238 \\
\hline 270 & 0.326 & 0.387 & 0.496 & 0.0206 & 0.0984 & 0.161 & 0.215 \\
\hline 280 & 0.296 & 0.352 & 0.452 & 0.0185 & 0.0895 & 0.147 & 0.196 \\
\hline 290 & 0.269 & 0.323 & 0.413 & 0.0168 & 0.0809 & 0.133 & 0.179 \\
\hline
\end{tabular}


TABLE V

SECONDARY TARGET TOTAL ATTENUATION COEFFICIENTS $\left(\mu_{k}\right)$

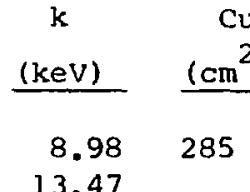
$\mathrm{Cu}$

$13.47 \quad 149$

$\begin{array}{lll}15 & 73.9 & 112\end{array}$

$20.00 \quad 33.7$

52.5

Mo

$\left(\mathrm{cm}^{2} / \mathrm{g}\right)$

$\mathrm{Ag}$

$\left(\mathrm{cm}^{2} / \mathrm{g}\right)$

$\mathrm{Ba}$

$\mathrm{Gd}$

25.51

32.7

28.1

13.1

82.2

39.4

63.1
29.0

92.3
42.9

118

5.51

30

37.44

10.8

17.4

18.1

9.60

55.8

36.6

$40 \quad 4.82$

$50 \quad 2.59$

\subsection{1}

4.28

12.9

6.97

17.1

9.38

$\left(\mathrm{cm}^{2} / g\right)$

$\left(\mathrm{cm}^{2} / \mathrm{g}\right)$

$\begin{array}{r}Y b \\ \left(\mathrm{~cm}^{2} / \mathrm{g}\right) \\ \hline\end{array}$

50.24

2.41

4. 25

5.75

9.73

14.6

19.1

5.48

29.1

60

1.58

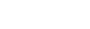

2.86

70
76.11

80

88.00

90

100

109.65

110

120

130

140

150

160

170

1.70

2.86

3.88

1.95

2.64

24.0

13.7

6.82

8.98

3.80

18.5

7.54

11.2

180

0.756

1.20

1.43

0.889

0.573

0.684

1.09

1.93

1.46

0.860

0.375

0.554

0.319

0.456

0.697

1.14

0.577

0.921

0.383

0.490

0.759

0.244

0.329

0.417

0.636

0.286

0.364

0.539

0.201

0.256

0.322

0.459

0.186

0.230

0.289

0.413

0.366

0.163

0.194

0.261

0.328

0.154

0.182

0.240

0.295

0.270

0.170

0.220

0.246

0.152

0.204

0.229

0.145

0.190

0.213

0.139

0.180

0.200

0.161

0.188

0.154

0.179

5.70

7.81

2.95

13.5

0.130

0.148

0.169

3.95

5.55

9.74

280

0.116

0.124

0.143

0.161

2.89

2.18

4.06

3.08

5.05

0.113

0.122

1.71

2.41

1.93

3.01

1.36

1.59

0.921

1.31

0.781

1.10

0.942

0.812

0.709

0.620

0.548

0.494

0.444

0.402

0.370

0.339

0.314

0.291

0.274

0.257

6.89

3.83

2.42

1.98

1.63

1. 8

1. .7

1. .11

0.870

0.766

0.682

0.609

0.543

0.494

0.452

0.414

0.238

0.379

0.222

0.348

0.210

0.197

0.327

0.303 
TABLE V (cont)

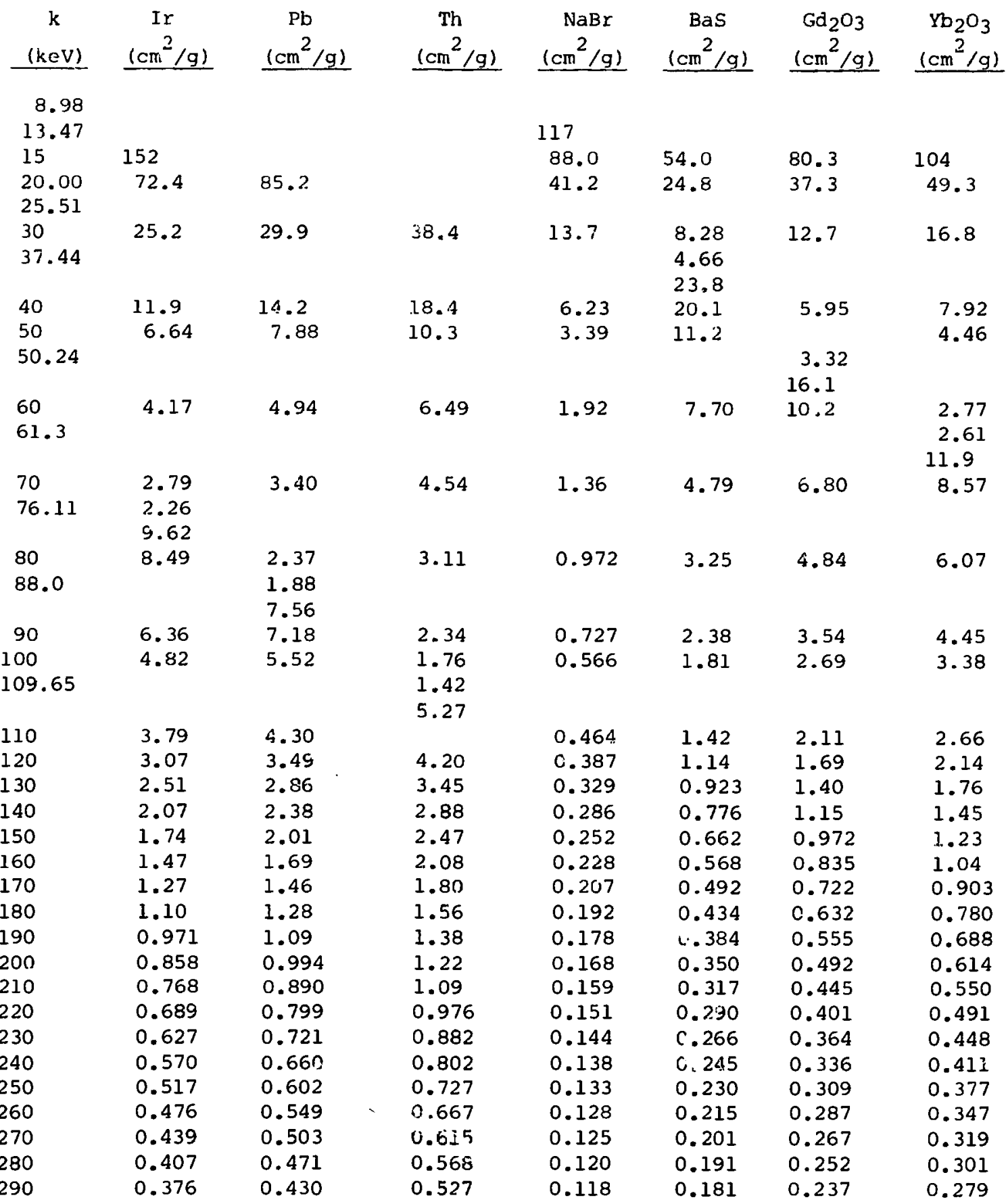




$$
\begin{aligned}
& d I_{\text {coh }}=\left(I_{\text {primary }} / r_{r}^{2}\right) \\
& x\left(A_{f} / \sin \theta\right)\left(d \sigma_{\operatorname{coh}} / d \Omega\right) \\
& x \quad \exp \left\{-\mu_{k} x / \sin \theta\right. \\
&\left.-\mu_{k} x / \cos \theta\right\}
\end{aligned}
$$$$
x \quad d x
$$

Integration over the total thickness $t$ of the target, with $6=45^{\circ}$, gives

$$
\begin{aligned}
I_{\text {coh }} & =I_{\text {primary }}\left(A_{f} / r_{r}^{2}\right) \\
& \times \frac{d \sigma_{c o h} / d \Omega}{2 \mu_{k}} \\
& \times\left[1-\exp \left\{-2 \sqrt{2} \mu_{k} t\right\}\right],
\end{aligned}
$$

where $I_{c o h}$ is in units of photons/s-mA-keV-sr.

The probability of coherent interaction is given by the Thomson scattering equation with corrections for electron binding

$$
\begin{aligned}
\frac{d \sigma_{c o h}}{d \Omega} & =\frac{r_{o}^{2}}{2}(1+\cos \phi) \\
& \times\left[\mathrm{F}_{\mathrm{q}, \mathrm{z}}\right]^{2},
\end{aligned}
$$

where $r_{6}$ is the classical electron radium and $\phi$ is the scattering angle. The term $\left(r_{12}^{2} / 2\right)\left(1+\cos ^{2} \phi\right)$ is the Thomson scattering cross section from one electron. $F$ is a form factor representing the probability that the recoil monentum $q$ is transferred to the $Z$ electrons of an atom without energy absorption. We used Cromer' ${ }^{369}$ form factors in this calculation. The $\mathrm{d} \sigma_{(\mathrm{c})} / \mathrm{d} \Omega 2$ values for $\phi=91^{\circ}$ are given in Table VI for the targets used.

\section{E. Incoherently Scattered Photons}

In Compton or incoherent seatter, a photon with energy $k$ interacts with the atomic electrons in the layer $\mathrm{dx}$ and is reradiated with lower energy $k^{\prime}$. For $90^{\circ}$ scatter

$$
k^{\prime}=\frac{k}{1+\left(k / m_{0} c^{2}\right)},
$$

where $k / m_{11} c^{2}$ is the incident photon energy in electron rest-mass units. Solving Eq. (14) for $k$ and differentiating gives the incident energy interval $\mathrm{dk}$ in terms of the scattered energy interval d.t' so that

$$
d k=\frac{d k^{\prime}}{\left\{1-\left(k^{\prime} / m_{0} c^{2}\right)\right\}^{2}} .
$$

Incoherently scattered photon intensities can be calculated from the third term in Eq. (6). The incoherent scattering coefficient $\sigma_{\text {inc }}$, which represents the probability of an incoherent interaction occurring summed over all angles of photon emission, must be replaced by $\mathrm{d} \sigma_{\mathrm{inc}} / \mathrm{d} \Omega$, which represents the probability that a photon with energy $k$ will irieract incoherently in the layer $\mathrm{dx}$ and that a scattered photon with energy $k$ ' will emerge in the direction of the detector within the solin angle $d \Omega$.

In traveling from $\mathrm{dx}$ to the target surface, the scat. tered photon is attenuated by exp $\left[-\mu_{k^{\prime}} x / \cos \theta\right]$, where $\mu_{k}$ ' is the total attenuatis coefficient of the scattered photon with energy $k$ '.

Thus the incoherently scattered photen intensity leaving the target in the direction of the detector from layer $\mathrm{dx}$ is 
SECONDARY TARGET COHERENT SCATTERING COEFFICIENTS

$k$
$(k \in V)$

\section{5}

20

30

40

50

61.20

69.52

80

90

100

110

120

130

140

150

160

170

180

190

200

210

220

230

240

250

260

270

280

N

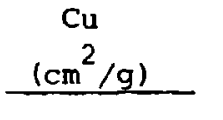

\subsection{2}

0.0160

0.00821

0.00376

0.00177

0.000948

0.000687

0.000523

0.000417

0.000346

0.000281

0.000229

0.000174

0.000136

0.000108

0.0000849

0.0000645

0.0000488

0.0000384

0.0000301

0.0000240

0.0000187

0.0000152

0.0000122

0.00000948

0.00000791

0.00000616

0.00000498

0.00000415 $(\mathrm{do} \mathrm{coh} / \mathrm{d} \Omega)$ FOR $\phi=90^{\circ}$

\begin{tabular}{|c|c|c|}
\hline $\begin{array}{r}\mathrm{Br} \\
\left(\mathrm{cm}^{2} / \mathrm{g}\right) \\
\end{array}$ & $\begin{array}{l}\text { Mo } \\
\left(\mathrm{cm}^{2} / \mathrm{g}\right)\end{array}$ & $\begin{array}{l}\mathrm{Ag} \\
\left(\mathrm{cm}^{2} / \mathrm{g}\right)\end{array}$ \\
\hline 0.0372 & 0.0572 & 0.0659 \\
\hline 0.0192 & 0.0309 & 0.0406 \\
\hline 0.00942 & 0.0113 & 0.0145 \\
\hline 0.00550 & 0.00672 & 0.00743 \\
\hline 0.00295 & 0.00433 & 0.00490 \\
\hline 0.00145 & 0.00242 & 0.00307 \\
\hline 0.000957 & 0.00160 & 0.00212 \\
\hline 0.000632 & 0.000960 & 0.00132 \\
\hline 0.000482 & 0.000672 & 0.00089 s \\
\hline 0.000392 & $0.00048 ?$ & 0.000614 \\
\hline 0.000330 & 0.000389 & 0.000453 \\
\hline 0.000284 & 0.000330 & 0.000375 \\
\hline 0.000237 & 0.000286 & 0.000314 \\
\hline 0.000196 & 0.000239 & 0.000268 \\
\hline 0.000164 & 0.000211 & 0.000231 \\
\hline 0.000134 & 0.000182 & 0.000209 \\
\hline 0.000111 & 0.000159 & 0.000181 \\
\hline 0.0000904 & 0.000136 & 0.000160 \\
\hline 0.0000754 & 0.000117 & 0.000142 \\
\hline 0.0000633 & 0.000102 & 0.000125 \\
\hline 0.0000516 & 0.0000854 & 0.000110 \\
\hline 0.0000432 & 0.0000728 & 0.0000949 \\
\hline 0.0000353 & 0.0000615 & 0.0000837 \\
\hline 0.0000288 & 0.0000527 & 0.0000731 \\
\hline 0.0000231 & 0.0600443 & 0.0000631 \\
\hline 0.0000187 & 0.0000369 & 0.0000543 \\
\hline 0.0000151 & 0.0000304 & 0.0000463 \\
\hline 0.0000116 & 0.0000247 & 0.0000391 \\
\hline 0.00000972 & 0.0000210 & 0.0000320 \\
\hline
\end{tabular}

\begin{tabular}{ll}
\multicolumn{1}{c}{$\begin{array}{c}\mathrm{Ba} \\
\left(\mathrm{cm}^{2} / \mathrm{g}\right)\end{array}$} & \multicolumn{1}{c}{$\mathrm{Gd}$} \\
\cline { 1 - 2 }$\left(\mathrm{cm}^{2} / \mathrm{g}\right)$ \\
\cline { 1 - 2 } 0.0732 & 0.0877 \\
0.0478 & 0.0540 \\
0.0225 & 0.0283 \\
0.00943 & 0.0145 \\
0.00557 & 0.00739 \\
0.00355 & 0.00414 \\
0.00272 & 0.00318 \\
0.00194 & 0.00239 \\
0.00135 & 0.00178 \\
0.000934 & 0.00133 \\
0.000627 & 0.000935 \\
0.000487 & 0.000705 \\
0.000392 & 0.000548 \\
0.000317 & 0.000429 \\
0.000267 & 0.000356 \\
0.000234 & 0.000294 \\
0.000204 & 0.000248 \\
0.000181 & 0.000208 \\
0.000161 & 0.000186 \\
0.000144 & 0.000168 \\
0.000129 & 0.000152 \\
0.000117 & 0.000142 \\
0.000105 & 0.000129 \\
0.0000938 & 0.000115 \\
0.0000851 & 0.000108 \\
0.0000759 & 0.0000973 \\
0.0000688 & 0.0000885 \\
0.0000605 & 0.0000789 \\
0.0000544 & 0.0000724 \\
&
\end{tabular}

\begin{tabular}{l}
\multicolumn{1}{c}{$\mathrm{Yb}$} \\
$\left(\mathrm{cm}^{2} / \mathrm{g}\right)$ \\
\hline 0.101 \\
0.0599 \\
0.0308 \\
0.0175 \\
0.00933 \\
0.00480 \\
0.00355 \\
0.0026 .3 \\
$0.002 \mathrm{C} 2$ \\
0.00158 \\
0.00120 \\
0.000912 \\
0.000651 \\
0.000487 \\
0.000393 \\
0.000328 \\
0.000275 \\
0.000237 \\
0.000216 \\
0.000196 \\
0.000176 \\
0.000161 \\
0.000144 \\
0.000133 \\
0.000120 \\
0.000112 \\
0.000101 \\
0.0000919 \\
0.0000863 \\
\end{tabular}


k
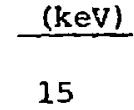

20

30

40

50

61.20

69.52

80

90

100

110

120

130

140

150

160

170

180

190

200

210

220

230

240

250

260

270

280

290
Ir $\left(\mathrm{cm}^{2} / \mathrm{g}\right)$

0.122

0.0717

0.0332

0.0204

0.0119

0.00598

0.00407

0.00291

0.00227

0.00181

0.00142

0.00112

0.000840

0.000617

0.000498

0.000404

0.000329

0.000280

0.000251

0.000223

0.000199

0.000179

0.000160

C. 000145

0.000132

0.000122

0,000110

0.0000996

0.0000921

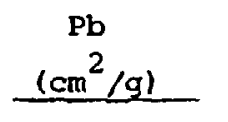

0.0823

0.0355

0.0217

0.0136

0.00689

0.00451

0.00317

0.00253

0.00193

0.00157

0.00126

0.00100

0.000779

0.000631

0.000500

0.000398

0.000334

0.000291

0.000249

0.000222

0.000195

0.000174

0.000158

0.000144

0.000132

0.000120

0.000110

0.000102
Th $\left(\mathrm{cm}^{2} / \mathrm{g}\right)$

0.0423

0.0234

0.0156

0.00919

0.00571

0.00381

0.00267

0.00211

0.00171

0.00143

0.00116

0.000945

0.000773

0.000618

0.000477

0.000392

0.000324

0.000272

0.000231

0.000205

$0.0001: 9$

0.000161

0.000145

0.000136

0.000123

0.000114

0.000105
NaBr $\left(\mathrm{cm}^{2} / \mathrm{g}\right)$

0.0299

0.0155

0.00764

0.00446

0.00239

0.00117

0.000768

0.000504

0.000381

0.000308

0.000258

0.000222

0.000185

0.000152

0.000127

0.000104

0.000036 .2

0.0000702

0.0000586

0.0000492

0.0000401

0.0000335

0.0000274

0.0000224

0.0000179

0.0000145

0.0000117

0.00007901

0.00000755

\begin{tabular}{lll}
\multicolumn{1}{c}{$\begin{array}{c}\mathrm{BaS} \\
\left(\mathrm{cm}^{2} / \mathrm{g}\right)\end{array}$} & & $\begin{array}{c}\mathrm{Gd}_{2} \mathrm{O}_{3} \\
\left(\mathrm{~cm}^{2} / \mathrm{g}\right)\end{array}$ \\
\cline { 1 - 1 } 0.0621 & & 0.0765 \\
0.0400 & & 0.0471 \\
0.0186 & & 0.0247 \\
0.00770 & & 0.0126 \\
0.00467 & & 0.00643 \\
0.00298 & & 0.00360 \\
0.00228 & & 0.00276 \\
0.00162 & & 0.00208 \\
0.00112 & & 0.00155 \\
0.000775 & 0.00115 \\
0.000520 & 0.000811 \\
0.000402 & 0.000612 \\
0.000322 & 0.000475 \\
0.000260 & 0.000372 \\
0.000218 & 0.000309 \\
0.000190 & 0.000255 \\
0.000165 & 0.000215 \\
0.000147 & 0.000180 \\
0.000131 & 0.000161 \\
0.000116 & 0.000146 \\
0.000105 & 0.000132 \\
0.0000949 & 0.000123 \\
0.0000851 & 0.000112 \\
0.0000760 & 0.0000998 \\
0.0000690 & 0.0000937 \\
0.0000615 & 0.0000844 \\
0.0000558 & 0.0000768 \\
0.0000490 & 0.0000685 \\
0.0000441 & 0.0000678 \\
& &
\end{tabular}

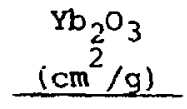

0.0891

0.0529

0.0272

0.0154

0.00821

0.00422

0.00312

0.00231

0.00177

0.00139

0.00105

0.000801

0.000572

0.000428

0.000346

0.000298

0.000242

0.000208

0.000190

0.000172

0.000155

0.000141

0.000126

0.000117

0.000105

0.0000984

0.0000887

0.0000807

0.0000758 


$$
\begin{aligned}
& \mathrm{dI}_{\text {inc }}=\left(\mathrm{I}_{\text {primary }} / \mathrm{r}^{2}\right) \\
& x\left(A_{f} / \sin \theta\right)\left(d_{o^{\prime n c}} / d \Omega\right) \\
& \lambda \quad \frac{1}{\left\{1-\left(k^{\prime} / m_{0} c^{2}\right)\right\}^{2}} \\
& x \exp \left\{-\mu_{k} x / \sin \theta\right. \\
& \left.-\mu_{k}, x / \cos \theta\right\} \\
& x d x \text {. }
\end{aligned}
$$

The term $1 /\left(1-k^{\prime} / m_{0} c^{2}\right)^{2}$ corrects for the change in the incident energy interval to the corresponding scattered energy interval and is obtained from Eq. (15). Integration of Eq. (16) over the total target thickness $\mathrm{t}$ with $\theta=45^{\circ}$ gives

$$
I_{\text {inc }}=I_{\text {primary }}\left(A_{f} / r_{r}{ }^{2}\right)
$$

$$
\begin{aligned}
& \times \frac{1}{\left\{1-\left(k^{\prime} / m_{o} c^{2}\right)\right\}^{2}} \\
& \times \frac{d \sigma_{i n c} / d \Omega}{\mu_{k}+\mu_{k}}
\end{aligned}
$$$$
x\left[1-\exp \left\{-\sqrt{\left.\left.2\left(\mu_{k}+\mu_{k^{\prime}}\right) t\right\}\right],}\right.\right.
$$

\section{F. Total Photons at the Detector}

The solid angle subtended it the detector is $A_{d} / r_{d}{ }^{2}$, where $A_{d}$ is the detector aperture area and $r_{b:}$ is the distance from the fluorescent diaphragm to the ' detector aperture. Thus, the total photon intensity incident on the detector is

where $I_{\text {inc }}$ is in units of photons/s-mA-keV-sr.

The c'uss section for photons interacting incoherently is given by the Klein-Nishina equation with corrections for electron binding 
TABLE VII

SECONDARY TARGET INCOHERENT SCA'TERING COEFFICIENTS $\left(d \sigma_{\text {ind }} / d \Omega\right)^{\prime}$ FOR $\phi=90^{\circ}$

\begin{tabular}{|c|c|c|c|c|c|c|c|c|}
\hline $\begin{array}{c}k^{\prime} \\
(k e V) \\
\end{array}$ & $\begin{array}{c}k \\
(\mathrm{kev}) \\
\end{array}$ & $\begin{array}{r}\mathrm{Cu} \\
\left(\mathrm{cm}^{2} / \mathrm{g}\right) \\
\end{array}$ & $\begin{array}{c}\mathrm{Br} \\
\left.\operatorname{cm}^{2} / \mathrm{g}\right) \\
\end{array}$ & $\begin{array}{c}\text { Mo } \\
\left(\mathrm{cm}^{2} / \mathrm{g}\right) \\
\end{array}$ & $\begin{array}{r}\mathrm{Pg} \\
2 \\
\left(\mathrm{~cm}^{2} / \mathrm{g}\right) \\
\end{array}$ & $\begin{array}{r}\mathrm{Ba} \\
\left(\mathrm{cm}^{2} / \mathrm{g}\right) \\
\end{array}$ & $\begin{array}{c}\mathrm{Gd} \\
\left(\mathrm{cm}^{2} / \mathrm{g}\right) \\
\end{array}$ & $\begin{array}{r}\mathrm{Yb} \\
2 \\
\left(\mathrm{~cm}^{2} / \mathrm{g}\right) \\
\end{array}$ \\
\hline 15 & 15.5 & 0.00678 & 0.00580 & 0.00571 & 0.00553 & 0.00509 & 0.00467 & 0.00438 \\
\hline 20 & 20.8 & 0.00744 & 0.00663 & 0.00640 & 0.00625 & 0.00561 & 0.00529 & 0.00505 \\
\hline 30 & 32.0 & 0.00815 & 0.00761 & 0.00728 & 0.00703 & 0.00645 & 0.00624 & 0.00602 \\
\hline 40 & 43.3 & 0.00834 & 0.00784 & 0.00760 & 0.00737 & 0.00675 & 0.00663 & 0.00651 \\
\hline 50 & 55.2 & 0.00834 & 0.00784 & 0.00772 & 0.00760 & 0.00688 & 0.00674 & 0.00665 \\
\hline 61.2 & 69.5 & 0.00815 & 0.00769 & 0.00766 & 0.00754 & 0.00688 & 0.00678 & 0.00668 \\
\hline 59.5 & 80.5 & 0.00796 & 0.00754 & 0.00753 & 0.00748 & 0.00684 & 0.00673 & 0.00661 \\
\hline 80 & 95.0 & 0.00767 & 0.00739 & 0.00734 & 0.00725 & 0.00680 & 0.00659 & 0.00654 \\
\hline 90 & 103 & 0.00749 & 0.00720 & 0.00716 & 0.00709 & 0.00667 & 0.00651 & 0.00637 \\
\hline 100 & 125 & 0.00720 & 0.00701 & 0.00697 & 0.00690 & 0.00658 & 0.00636 & 0.00630 \\
\hline 110 & 140 & 0.00706 & 0.00678 & 0.00684 & 0.00670 & 0.00645 & 0.00624 & 0.00623 \\
\hline 120 & 157 & 0.00682 & 0.00659 & 0.00559 & 0.00653 & 0.00623 & 0.00613 & 0.00602 \\
\hline 130 & 174 & 0.00663 & 0.00637 & 0.00634 & 0.00631 & 0.00592 & 0.00586 & 0.00581 \\
\hline 140 & 193 & 0.00635 & 0.00614 & 0.00612 & 0.00609 & 0.00566 & 0.00571 & 0.00560 \\
\hline 150 & 213 & 0.00611 & 0.00588 & 0.00590 & 0.00581 & 0.00544 & 0.00544 & 0.00536 \\
\hline 160 & 233 & 0.00588 & 0.00565 & 0.00565 & 0.00562 & 0.00526 & 0.00529 & 0.00522 \\
\hline .170 & 255 & 0.00569 & 0.00543 & 0.00552 & 0.00547 & 0.00504 & 0.00506 & 0.00508 \\
\hline 180 & 278 & 0.00545 & 0.00524 & 0.00527 & 0.00525 & 0.00487 & 0.00490 & 0.00487 \\
\hline 189 & 300 & 0.00527 & 0.00505 & 0.00506 & 0.00504 & 0.00474 & 0.00471 & 0.00466 \\
\hline
\end{tabular}




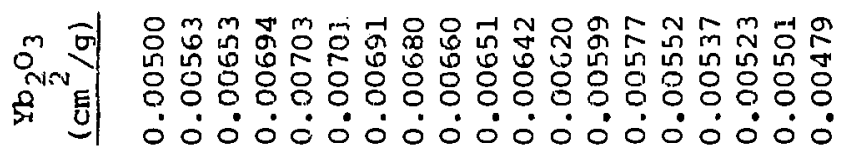

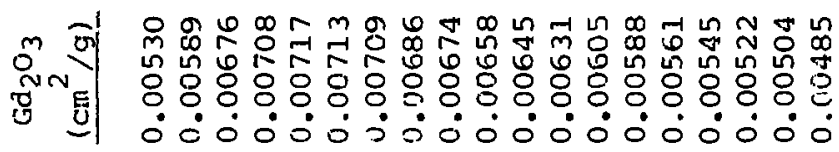

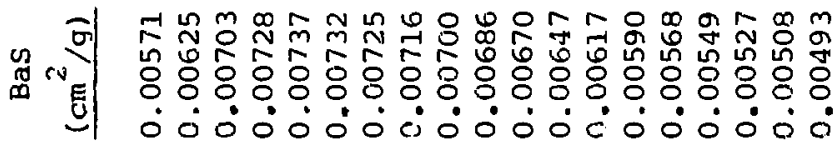

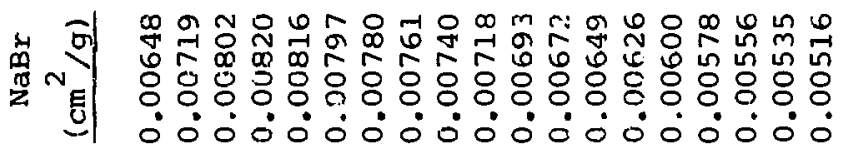

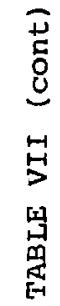

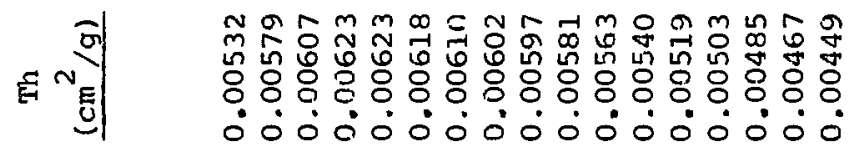

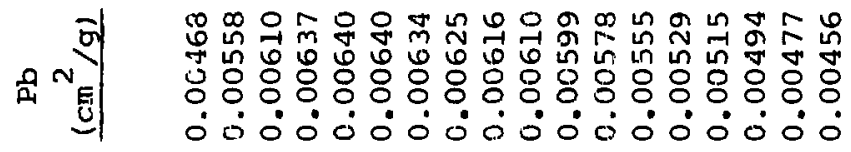

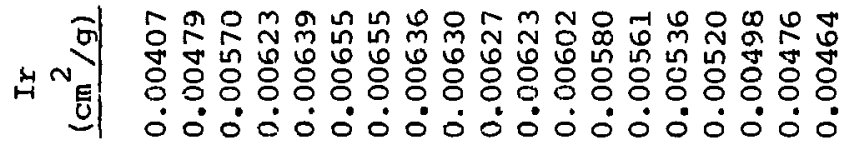

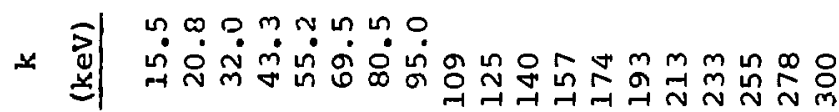

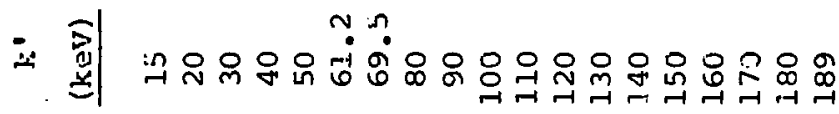


TABLE VI I I

SECONDARY TARGET TOTAL ATTENUATION COEFFICIENTS FOR SCATTERED PHOTONS $\left(\mu_{k},\right)$

\begin{tabular}{|c|c|c|c|c|c|c|c|}
\hline $\begin{array}{c}\mathrm{k}^{\prime} \\
(\mathrm{keV}) \\
\end{array}$ & $\begin{array}{c}\mathrm{Cu} \\
\left(\mathrm{cm}^{2} / \mathrm{g}\right) \\
\end{array}$ & $\begin{array}{c}3 r \\
\left(\mathrm{~cm}^{2} / g\right) \\
\end{array}$ & $\begin{array}{c}\text { Mo } \\
\left(\mathrm{cm}^{2} / \mathrm{g}\right) \\
\end{array}$ & $\begin{array}{c}\mathrm{Ag} \\
\left(\mathrm{cm}^{2} / \mathrm{g}\right) \\
\end{array}$ & $\begin{array}{c}\mathrm{Ba} \\
(\mathrm{cm} / \mathrm{g}) \\
\end{array}$ & $\begin{array}{c}\mathrm{Gd} \\
\left(\mathrm{cm}^{2} / \mathrm{g}\right) \\
\end{array}$ & $\begin{array}{c}\mathrm{Yb} \\
2 \\
\left(\mathrm{~cm}^{2} / \mathrm{g}\right) \\
\end{array}$ \\
\hline $\begin{array}{l}15 \\
19.25\end{array}$ & 89.1 & 105 & $\begin{array}{l}25.9 \\
13.1 \\
82.2\end{array}$ & 47.2 & 57.9 & 84.3 & 108 \\
\hline $\begin{array}{l}20 \\
24.30\end{array}$ & 30.3 & 47.5 & 75.3 & $\begin{array}{c}16.6 \\
9.60 \\
55.8\end{array}$ & 26.3 & 38.3 & 50.1 \\
\hline $\begin{array}{l}30 \\
34.88\end{array}$ & 9.10 & 14.7 & 23.6 & 31.0 & $\begin{array}{c}8.33 \\
5.48 \\
29.1\end{array}$ & 12.4 & 16.2 \\
\hline $\begin{array}{l}40 \\
45.74\end{array}$ & 3.90 & 5.48 & 10.4 & 14.0 & 20.2 & $\begin{array}{r}5.67 \\
3.80 \\
18.5\end{array}$ & 7.24 \\
\hline $\begin{array}{l}50 \\
54.76\end{array}$ & 1.50 & 3.24 & 5.24 & 7.03 & 10.7 & 14.3 & $\begin{array}{l}3.83 \\
2.95 \\
13.5\end{array}$ \\
\hline $\begin{array}{l}61.20 \\
66.24\end{array}$ & 1.07 & 1.70 & 2.86 & 3.88 & 5.79 & 7.93 & 9.57 \\
\hline $\begin{array}{l}69.52 \\
75.07\end{array}$ & 0.741 & 1.18 & \pm .91 & 2.64 & 3.90 & 5.48 & 6.79 \\
\hline $\begin{array}{l}80 \\
90.28\end{array}$ & $\begin{array}{l}0.51 .2 \\
0.379\end{array}$ & $\begin{array}{l}0.776 \\
0.565\end{array}$ & $\begin{array}{l}1.87 \\
0.879\end{array}$ & $\begin{array}{l}1.67 \\
1.17\end{array}$ & $\begin{array}{l}2.52 \\
1.75\end{array}$ & $\begin{array}{l}3.15 \\
2.45\end{array}$ & $\begin{array}{l}4.45 \\
3.06\end{array}$ \\
\hline 100 & 0.294 & 0.418 & 0.634 & 0.837 & 1.23 & 1.75 & 2.18 \\
\hline 110 & 0.244 & 0.328 & 0.489 & 0.642 & 0.921 & 1.31 & 1.64 \\
\hline 120 & 0.206 & 0.264 & 0.380 & 0.491 & 0.702 & 0.996 & 1.24 \\
\hline 130 & 0.180 & 0.222 & 0.311 & 0.394 & 0.548 & 0.766 & 0.957 \\
\hline 140 & 0.161 & 3.188 & 0.254 & 0.318 & 0.434 & $0.59 . !$ & 0.741 \\
\hline 150 & 0.145 & 0.166 & 0.213 & 0.262 & 0.351 & 0.475 & 0.592 \\
\hline J.60 & 0.134 & 0.149 & 0.188 & 0.223 & 0.292 & 0.394 & 0.480 \\
\hline 170 & 0.124 & 0.136 & 0.166 & 0.195 & 0.247 & 0.326 & 0.393 \\
\hline 180 & 0.115 & 0.126 & 0.149 & 0.170 & 0.213 & 0.276 & 0.320 \\
\hline 189 & 0.111 & 0.118 & 0.137 & 0.155 & 0.189 & $0.2 \div 1$ & 0.285 \\
\hline
\end{tabular}


TABIE, VIII (cont)

\begin{tabular}{|c|c|c|c|c|c|c|c|}
\hline $\begin{array}{c}k^{\prime} \\
(\mathrm{keV}) \\
\end{array}$ & $\begin{array}{c}\mathrm{Ir}^{-} \\
\left.\operatorname{scm}^{2} / \mathrm{g}\right) \\
\end{array}$ & $\begin{array}{c}\mathrm{Pb} \\
\left(\mathrm{cm}^{2} / \mathrm{g}\right) \\
\end{array}$ & $\begin{array}{c}\text { Th } \\
(\mathrm{s} / \mathrm{m}) \\
\end{array}$ & $\begin{array}{c}\mathrm{NaBr} \\
\left(\mathrm{cm}^{2} / \mathrm{g}\right) \\
\end{array}$ & $\begin{array}{c}\mathrm{BaS} \\
\left(\mathrm{cm}^{2} / \mathrm{g}\right) \\
\end{array}$ & $\begin{array}{r}\mathrm{Gd}_{2} \mathrm{O}_{3} \\
2 \\
\left(\mathrm{~cm}^{2} / \mathrm{g}\right) \\
\end{array}$ & $\begin{array}{r}\mathrm{Yb}_{2} \mathrm{O}_{3} \\
2 \\
\left(\mathrm{~cm}^{2} / \mathrm{g}\right) \\
\end{array}$ \\
\hline $\begin{array}{l}15 \\
19.25\end{array}$ & 139 & & & 84.5 & 49.6 & 73.3 & 95.0 \\
\hline $\begin{array}{l}20 \\
24.30\end{array}$ & 65.8 & 77.9 & & 37.3 & 22.4 & 33.3 & 44.1 \\
\hline $\begin{array}{l}30 \\
34.88\end{array}$ & 21.5 & 25.6 & 32.7 & 11.6 & $\begin{array}{c}7.08 \\
4.66 \\
23.8\end{array}$ & 10.8 & 14.3 \\
\hline $\begin{array}{l}40 \\
45.74\end{array}$ & 9.87 & 11.6 & 15.1 & 5.13 & 16.5 & $\begin{array}{l}4.95 \\
3.32 \\
16.1\end{array}$ & 6.39 \\
\hline $\begin{array}{l}50 \\
34.76\end{array}$ & 5.23 & 5.96 & 7.91 & 2.57 & 8.76 & 12.4 & $\begin{array}{r}3.39 \\
2.61 \\
11.9\end{array}$ \\
\hline $\begin{array}{l}61.20 \\
66.24\end{array}$ & $\begin{array}{l}2.82 \\
2.26 \\
9.62\end{array}$ & 3.40 & 4.54 & 1.36 & 4.75 & 6.90 & 8.43 \\
\hline $\begin{array}{l}69.52 \\
75.07\end{array}$ & 8.30 & $\begin{array}{l}2.36 \\
1.88 \\
7.56\end{array}$ & 3.09 & 0.956 & 3.21 & 4.78 & 5.99 \\
\hline 80 & 5.55 & 6.34 & 2.04 & 0.639 & 2.08 & 3.06 & 3.93 \\
\hline 90.23 & 3.92 & 4.74 & $\begin{array}{l}1.42 \\
5.27\end{array}$ & 0.473 & 1.45 & 2.15 & \\
\hline 100 & 2.76 & 3.14 & 3.81 & 0.357 & 1.03 & 1.54 & 1.93 \\
\hline 110 & 2.07 & 2.37 & $2.8 \varepsilon$ & 0.285 & 0.776 & 1.15 & 1.46 \\
\hline 120 & 1.54 & 1.79 & 2.18 & 0.235 & 0.597 & 0.882 & 1.11 \\
\hline 130 & 1.21 & 1.38 & 1.70 & 0.201 & 0.470 & 0.682 & 0.856 \\
\hline 140 & 0.934 & 1.08 & 1.32 & 0.173 & 0.377 & 0.532 & 0.666 \\
\hline 150 & 0.736 & 0.860 & 1.06 & 0.155 & 0.308 & 0.428 & 0.535 \\
\hline 160 & 0.605 & 0.701 & 0.856 & 0.141 & 0.259 & 0.357 & 0.436 \\
\hline 170 & 0.498 & 0.576 & 0.698 & C. 130 & 0.222 & 0.298 & 0.359 \\
\hline 180 & 0.414 & 0.477 & 0.571 & 0.122 & 0.194 & 0.254 & 0.294 \\
\hline 189 & 0.351 & 0.398 & 0.485 & 0.115 & 0.174 & 0.223 & 0.263 \\
\hline
\end{tabular}




$$
\begin{aligned}
& I_{\text {detector }}=\left(A_{d} / r_{d}^{2}\right) \\
& x\left[I_{\alpha}+I_{K_{B}}+I_{c o h}+I_{\text {inc }}\right] \\
& x \exp \left[-(\mu t)_{A l}-\Sigma(\mu t)_{\text {det }}\right],
\end{aligned}
$$

where $\mu$ is the appropriate total attenuation coefficient for the fluorescent and scattered photon energy. The exponentiais correct for the aluminum L-line filter and the intervening Mylar, air, and detector window attenuation. $I_{K_{a}}, I_{K_{q}}, I_{\text {coh }}$, and $I_{\text {inr }}$ are given by Eqs. (9), (10), (12), and (17), respectively.

\section{COMPARISON OF MEASUREMENT AND THEORY}

\section{A. Undistorted Scattered Spectra}

Typical undistorted scattered spectra calculated for secondary targeis of $Z=42,64$, and 82 are shown in Fig. 16 for a $250-\mathrm{kV}$ potential. The coherent continuurn calculated from Eq. (12), the incoherent continuum calculated from Eq. (17), the total continuum, and the tungsten $K$ lines are shown, but the fluorescent $\mathrm{K}$ lines crcited in the secondary targets have been omitted. There are four $\mathrm{K}$ edges and four $K$ lines. The coherently scattered primary and secondary $K$ edges fnd the primary $K_{a}$ and $K_{d}$ lines appear, as well as the ircoherently scattered primary and secondary $K^{\prime}$ edges anci the primary $K_{r}{ }^{\prime}$ and $K_{r}^{\prime}$ lines. 'The location of the tungsten $K$ edges and $K$ lines, together with the secondary $K$ eilges, are listed in Table III.

For purposes of discussion, the scattered spectra in Fig. 16 may be divided into three energy regions: a lower region $k<K$ lines, a middle region $K$ lines $<k$ $<k^{\prime}{ }_{1}$, and an upper region $k>k_{0}^{\prime}$. In the lower region, the coherent and incoherent interactions contribute to the intensity, with the former tending to

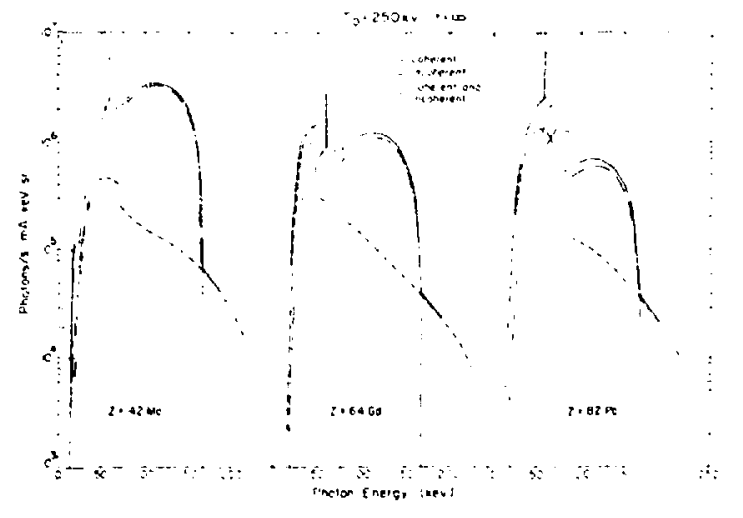

Fig. 16.

Calcuiated coherent and incoherent spectra for $Z=42,64$, and 82 . Secondary $K$ lines are not included.

dominate. In the middle region, the incoherent interaction is responsible for most of the scattered $i_{1}$ tensity. In the upper region, only coherent scattering occurs. Thus, the calculated total $90^{\circ}$ scattered spectra possess the romplicated structured shape shown in Fig. 16. The incoherent cutoff energy $k$ ', given by $\mathrm{Eq}$. (14) varies with operating potential. having, values of $84,116,144,168$, and $189 \mathrm{keV}$ for potentials of $100,150,200,250$, and $30 k, \mathrm{kV}$, respectively.

\section{B. Comparison of Spectral Distributions}

The spectral distribution at the detector is given by Eq. (19). As with the primary heam, the spectra are distorted by the detectors, and the measurements show that each of the three detectors distorts the spectra differently. To compare theory with measurement, the calculated spectra were distorted using the Monte Carlo program developed by Israel. ${ }^{16}$ As described above, the geometry and resolution of the detector are input data, and the program distorts the calculated spectrum so that it can be compared directly with measurement. Results are shown in Figs. 4-14, where the solid lines are the distorted calculated spectra. The structured shapes appearing in the calculated spectra of Fig. 16 are for the most part obscured by detector distortions.

Figure 4 gives the silicon detector results for $\mathbf{Z}=$ 29. 35. and 42 and potentials of 100,200 . and 300 
keV. The ineasured and calculated $\mathrm{K}$-photon intensities tend to agree, but the poor silicon detector efficiency causes the counting rate to be low and the measured points to scatter appreciably, making it difficult to compare the results of the $90^{\circ}$ scattered spectra. Figures $5-8$ give the germanium detector results for $42 \leq Z \leq 90$, and the measured and calculated $K$-photon intensities tend to agree. Counting rates are higher and measurements of the $90^{\circ}$ scattered spectra are in better agreement with calculation; the points tend to scatter about the calculated line. The largest discrepancies occur at $<20 \mathrm{keV}$, caused in part by large detector leakage currents. Figures 9-12 give the NaI detector results for $42 \leq \mathrm{Z} \leq 90$, and the agreement is quite good. Again, poorest agreement occurs at $<20 \mathrm{keV}$, where measured Compton scatter is larger than calculated. Figures 13 and 14 give the spectra obtained with three different target thicknesses instead of three different potentials. For a potential of $250 \mathrm{kV}$, copper. molybdenum. gadolinium, and lead spectra measured with the three different detectors are shown. For these measurements, metallic gadolinium was used instead of the oxide powder. Measured and calculated spectra show the same trend when the target thickness is varied. The discrepancies are similar to those described above and appear to be associated with the type of detector.

In summary, although there are regions where large discrepancies occur, particularly at $<20 \mathrm{keV}$, the overall agreement between measured and calculated spectra is good and tends to be within $20 \%$.

\section{Comparison of Total Intensities}

The total number of $K_{a}$ plus $K_{i}$ photons emitted from the target can be estimated from the spectrometer measurements by summing the total number of counts under the photo and escape peaks and subtracting the continuum. This prccedure was applied to spectral measurements obtained at potentials of 100,200 , and $300 \mathrm{kV}$ (Figs. 4-12) and to spectral measurements obtained at 150 and $250 \mathrm{kV}$ (not shown). The total number of $\mathrm{K}$ photons emitted from the target, as estimated from the spectrometer measurements, with corrections for aluminum and detector filtration, is plotted as a function of primary potential $T_{1}$ in Fig. 17 for each of the 10 secondary

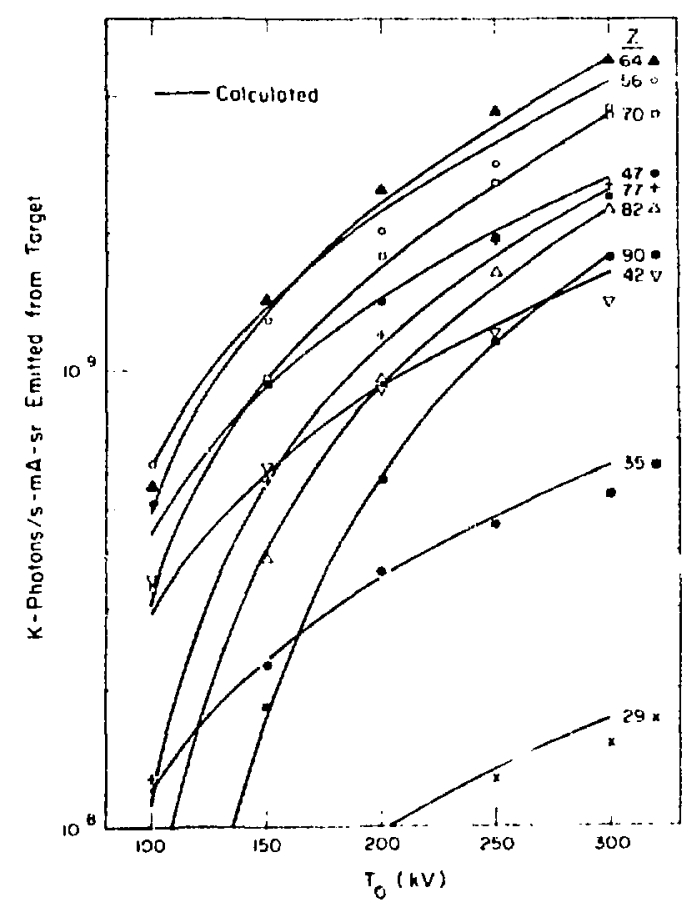

Fig. 17.

Calculated total intensity in photons compared to spectral measurements.

targets. The total $K_{a}, K_{\beta}$ intensity was also calculated from Eqs. (9) and (10), and the results are given by the solid curves in Fig. 17. In all cases, the measured points are within $15 \%$ of the calculated curves.

As an additional check on the theory, the intensity from the targets was measured in roentgens with a free-air ionization chamber. In Fig. 18, the measured intensiti. $815 \mathrm{~cm}$ from the secondary target are plot ted as a function of primary potential for each of the 10 secondary targets. The total calculated $K_{\alpha}, K_{\not j}$, coherent, and incoherent photon intensity, with corrections for aluminum and air attenuation, is also given in Fig. 18 by the solid curves for a secondary target-to-detector distance of $15 \mathrm{~cm}$. Because the free-air chamber measured the scattered radiation and the $K$-line radiation, the scattered contribution. was included in the calculation. For the higher $\mathrm{Z}$ materials. the measured points tend to fall above the calculated curves at the higher potentials, but in all cases, the points are within $20 \%$ of the calculated curves. 


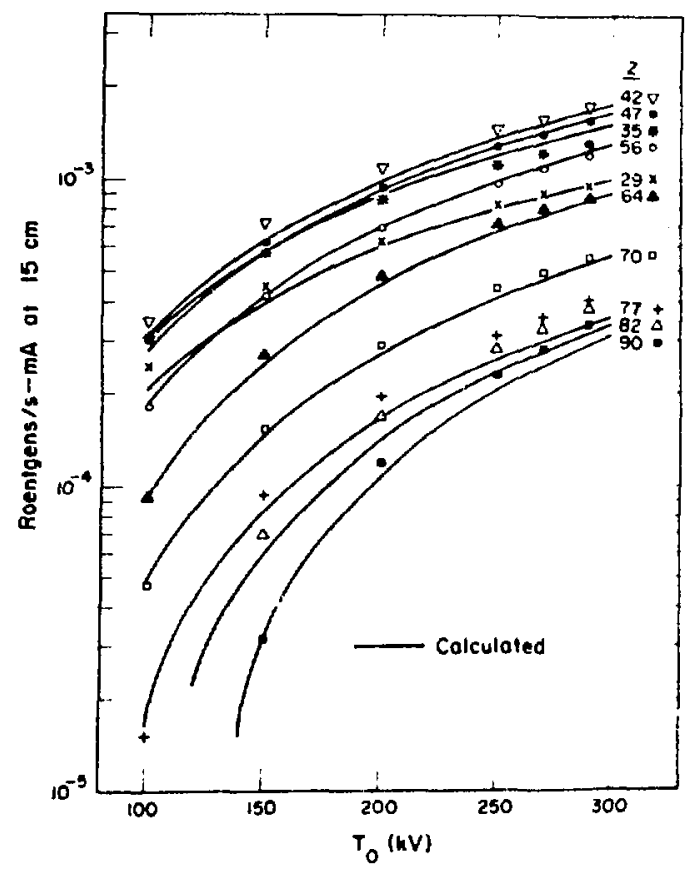

Fig. 18.

Calculated total intensity in roentgens com. pared with free-air chamber measurements.

\section{OPTIMIZA'TION OF K-PHOTON INTEN. SITY AND PURITY}

\section{A. Target Thickness}

The target thickness appears in the (1-e * $\left.{ }^{\prime}\right)$ terms of the K-photon equations, Eqs. (9) and (10), and the scatter equations, Dqs. (12) and (17). The K photon and scatter intensities increase with thickness, approaching a maximum value exponentially. Because $1-e^{-\mu t}=1$ when $t=\infty$, maximum in . tensities are obtained with infinitely thick targets. Intensities were calculated for thicknesses in the range $0.01 \leq \mathrm{t} \leq 10 \mathrm{~g} / \mathrm{cm}^{2}$ and were compared with the intensities obtained with infinitely thick targets. Figure 19 gives the ratio of the K-photon intensity obtained with a finite target to the intensity obtained with an infinitely thick target as a function of target thickness for excitation potentials of 150 and $250 \mathrm{kV}$. The ratio represents the fraction of the max imum K-photon intensity attainable with a given

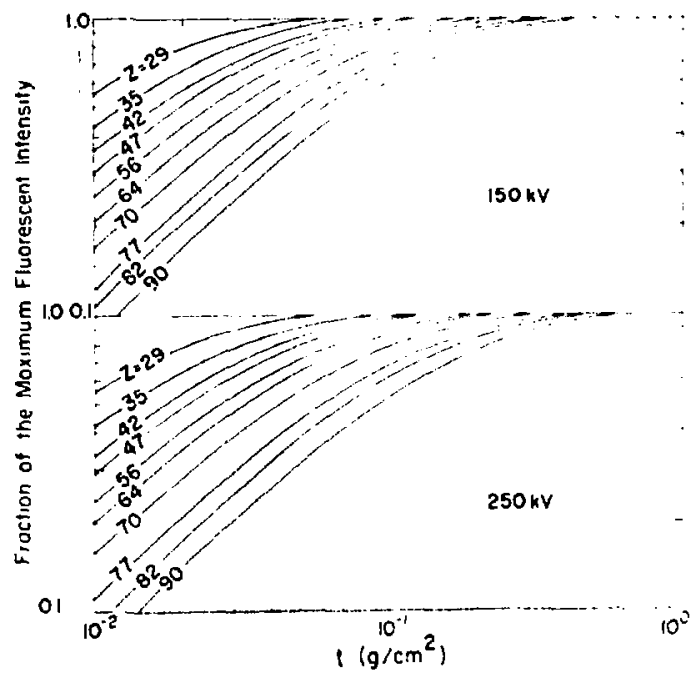

Fig. 19.

Fraction of the maximum attainable $K$ intensity as a function of target thickness. The ordinate is the ratio of $K$ intensity at a given target thickness to that obrained with an infinitely thick target.

target thickness with all other variables held constant. A similar plot giving the fraction of the maximum scattered intensity as a function of thickuess is shown in Fig. 20. Because the dependence on $\mathrm{Z}$ is of interest here, these and all other calculations performed in the remainder of this report were for the 10 elemental targets only. Values of $\tau_{k}, \mu_{k}, \mathrm{~d} \sigma_{\mathrm{cuh}} / \mathrm{d} \Omega$, $\mathrm{d} \sigma_{\text {inc }} / \mathrm{d} \Omega$, and $\mu_{k^{\prime}}$ are given in Tables IV.VIII; $\mu_{K_{\alpha}}$ and $\mu_{\text {hig }}$ are listed in Table III.

The K-photon curves in Fig. 19 behave differently with atomic number than do the scatter curves in Fig. 20. For a given target thickness, the fraction of the maximum K-photon intensity is largest for the lowest $Z$ and decreases as $Z$ increases, whereas the fraction of the maximum scattered intensity is largest for the highest $\mathrm{Z}$ and decreases as $\mathrm{Z}$ decreases.

The $K$.photon behavior with $Z$ is explained by considering that $\mathrm{K}$-photon energies increase with $\mathbf{Z}$, and attenuation coefficients are large at low energies, tending to decrease as energy increases. For example, the $K_{a}$ energy for $Z=29$ is $8 \mathrm{keV}$ and $\mu_{K_{a}}=$ 50.2 (Table III), whereas the $K_{a}$ energy for $Z=90$ is $92 \mathrm{keV}$ and $\mu_{K_{\alpha}}=2.21$. Hence, the $8-\mathrm{keV}$ photon is 


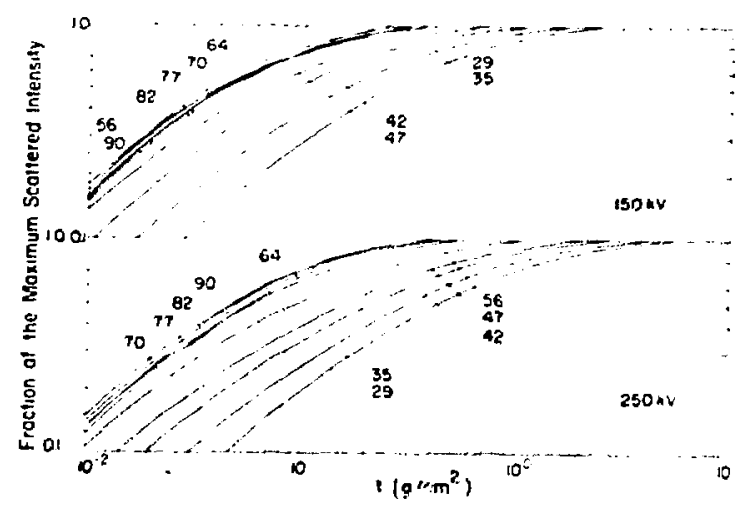

Fig. 20.

Fraction of the maximum attainable scattered intensity as a function of target thickness. The ordinate is the ratio of scattered intensity at a given target thickness to that obtained with an infinitely thick target.

strongly attenuated in leaving the target, and only those photons produced near the surface can escape. On the other hand, the $92-\mathrm{keV}$ photons suffer far less attenuation and can escape from a much greater target depth. Thus, to obtain a given fraction of the maximum K-photon intensity, much thicker targets are required for $Z=90$ than for $Z=29$. This is shown in Fig. 21, where the thickness required to achieve fractions of $0.5,0.75,0.9$, and 0.99 of the maximum attainable $K$-photon intensity are given as a function of $Z$ for potentials of 150 and $250 \mathrm{kV}$. The curves increase rapidly with $Z$, but are weakly dependent on the primary putential. The discontinuities are caused by the tungsten $K_{\alpha} \cdot(58.8 \mathrm{keV})$ and $K_{p^{-}}-(67.6 \mathrm{keV})$ lines in the primary beam which can excite $K$ photons only above the $Z=68 \mathrm{~K}$ edge $(57.5 \mathrm{keV})$ and the $Z=73 \mathrm{~K}$ edge $(67.4 \mathrm{keV})$, respectively.

The behavior of scattered radiation with $\mathrm{Z}$ is more difficult to explain. The scattered primary photon energy distribution is similar in each target. Tables $V$ and VIIl, which give $\mu_{k}$ and $\mu_{k}$ as a function of energy, show that for a given energy the total attenuation coefficient tends to increase as $Z$ increases. Hence, for the same target thicknesses, the scattered photons leaving the targets suffer greater attenuation in the higher $\mathrm{Z}$ materials. This trend is affected to some extent by the target K-edge discontinuities when they occur near the tungsten $\mathrm{K}$-line

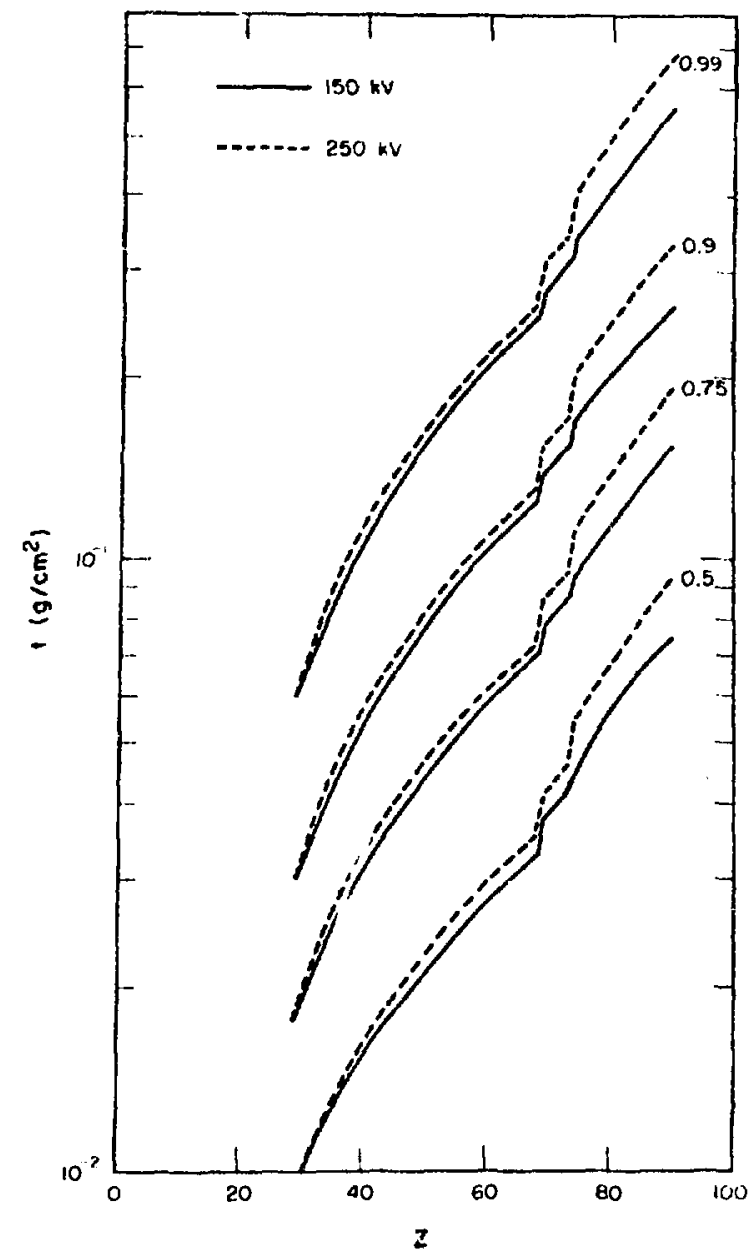

Fig. 21.

Target thicknesses required to obtain fractions of $0.5,0.75,0.9$, and 5.99 of the maximum attainnble $K$ intensity.

and $K$-edge energies. As a result, the fraction of maximum scattered intensity curves are only weakly dependent on atomic numbers of $Z>60$. This can be seen more clearly in Fig. 22, where the thicknesses required to obtain fractions of $0.25,0.5,0.75,09$, and 0.99 of the maximum attainable scattered intensity are given as a fraction of $Z$ for potentials of 150 and $250 \mathrm{kV}$. The curves at first decrease rapidly with $Z$, but level off and remain relatively constant above $Z=60$. Also, the scattered intensity is more strongly dependert w the potential than on the K-photon intensity. 


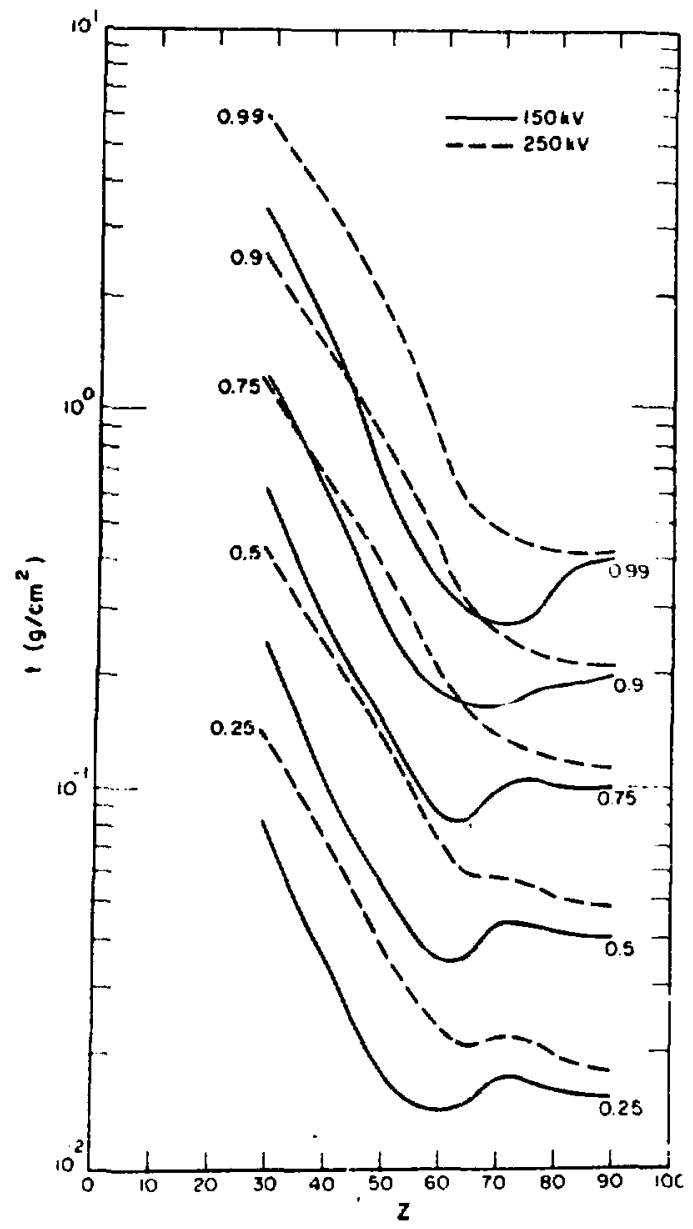

Fig. 22.

Target thicknesses required to obtain fractions of $0.25,0.5,0.75,0.9$, and 0.99 of the maximum attainable scattered intensity.

In most applications, target thicknesses are required that maximize either the $K$-photon intensity or the purity. Purity is plotted in Fig. 23 for the 10 elements as a function of target thickness for potentials of 150 and $250 \mathrm{kV}$. Over the thickness range studied, the purity of the low-Z targets $(29,35,42)$ is highest at smallest thicknesses and decreases as thickness increases. Purity is relatively constant with thickness for $Z=47,56,64$, and 70 . For the high- $\mathrm{Z}$ targets $(77,82,90)$, purity is lowest for the thinnest targets and increases as thickness increases, tending to level off at large thicknesses.

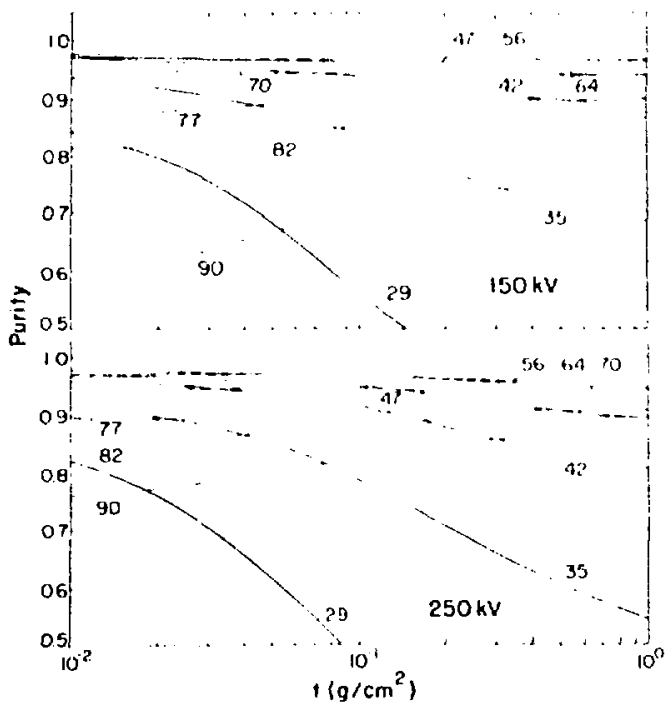

Fig. 23.

Purity as a function of target thickness.

The purity of those target thicknesses giving 0.5 , $0.75,0.9$, and 0.99 of the maximum attainable $K$ photon intensity is shown in Fig. 24 as a function of $Z$ for potentials of 150 and $250 \mathrm{kV}$. For $Z<50$, purity decreases as the fraction of the maximum attainable $K$-photon intensity increases. For $Z>50$, purity increases as the fraction increases. Hence, for $Z<50$ one must choose between intensity and purity. For $Z$ $>50$, thicker targets give higher intensity and purity.

In summary, maximum K-photon intensity with the minimum scatter and maximum purity is obtained with target thicknesses labeled 0.99 in Fig. 21. Thicknesses larger than these will significantly increase the scatter but not the K-photon intensity. For $\mathrm{Z}<50$, purity can be improved by using thinner targets and sacrificing $K$-photon intensity. For example. at $Z=29$ and $T_{0}=250 \mathrm{kV}$, a target thickness of 0.01 instead of $0.06 \mathrm{~g} / \mathrm{cm}^{2}$ increases the purity from 0.62 to 0.90 , but decreases the K-photon intensity by one-hall.

Target thicknesses labeled 0.99 in Fig. 21 for $\mathrm{T}_{0}=$ $250 \mathrm{kV}$ were used in the remainder of the calculations discussed in this report. 

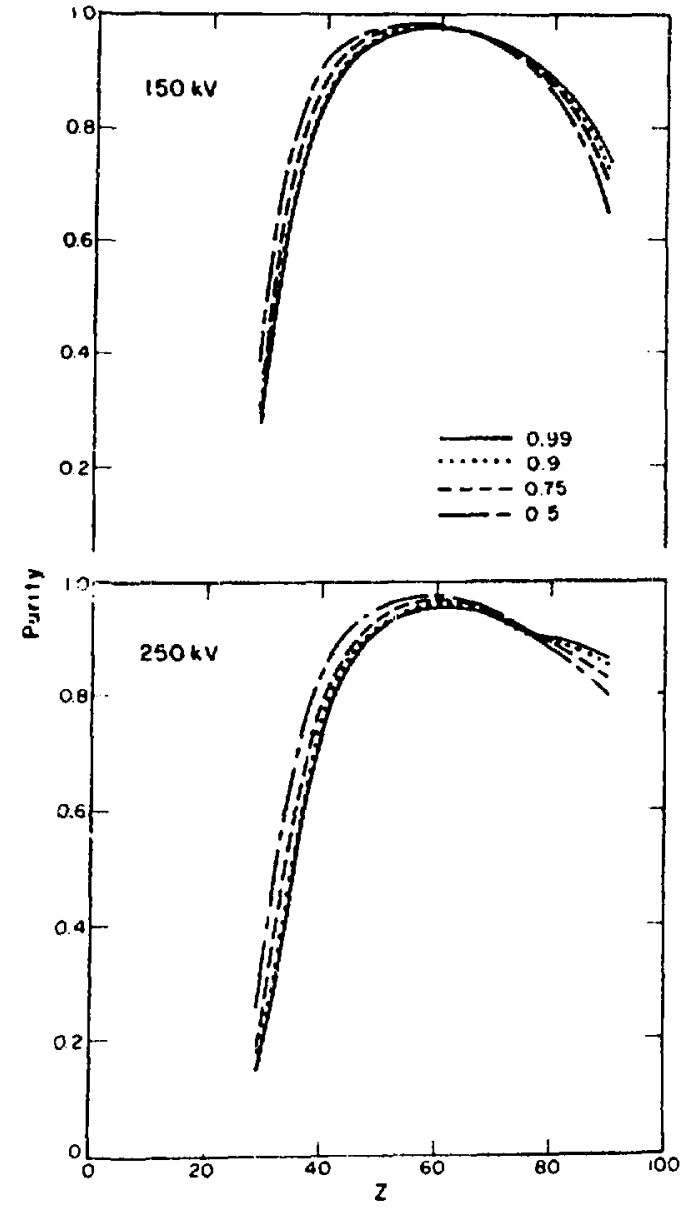

Fig. 24.

Purity as a function of $Z$ for target thicknesses that give $0.5,0.75,0.9$, and 0.99 of the maximum $K$ intensity.

\section{B. Primary Potential}

The units in which an instrument is calibrated depend upon the intended application. In general, radiation laboratory instruments are calibrated in photons, $x$-ray astronomy and nuclear test detectors in ergs, and personnel dosimeters and health physics instruments in roentgens. Because the intensity of each unit is of interest, and purity varies wi'h the unit of measurement, calculations were per'ormed for each of these units.

The potential appears in the $\mathrm{K}$ photon and scatter equations in the $I_{\text {primary }}$ term, which represents the spectral distribution of the primary beam (Fig. 1). Total K-photon intensities were calculated from Eqs. (9) and (10), and total scattering intensities by summing Eqs. (12) and (17) over the photon energy range.

In Fig. 25, K-photon and scattered intensities are plotted in units of photons, ergs, and roentgens as a function of $\mathrm{Z}$ for each of the five potentials. The $\mathrm{K}$ photon curves are strongly dependent on $Z$, varying in intensity by one to two orders of magnitude. The curves tend to be bell-shaped, with the intensity peaking near $Z=50-60$. At higher potentials, the curves tend to rise in the upper $Z$ region. The shape of the scatter curves is similar for a fixed potential, being relatively flat at low $Z$, rising between $Z=60$. 70 before leveling off again. Scatter varies by no more than a factor of 2 to 3 over the range $29 \leq \mathrm{Z} \leq$ 90.

Purity is plotted in Fig. 26 as a function of $\mathrm{Z}$ for the five potentials. Although purity is a dimensio. nless ratio, it varies with the intensity units. The photon curves peak at $Z=50-60$ and decrease at low and high $Z$. Thus intensity and purity curves peak in the middle- $Z$ region and fall off at both ends. Although similar trends are observed for ergs, purity is considerably less at low Z. For example, for $Z_{1}=29$
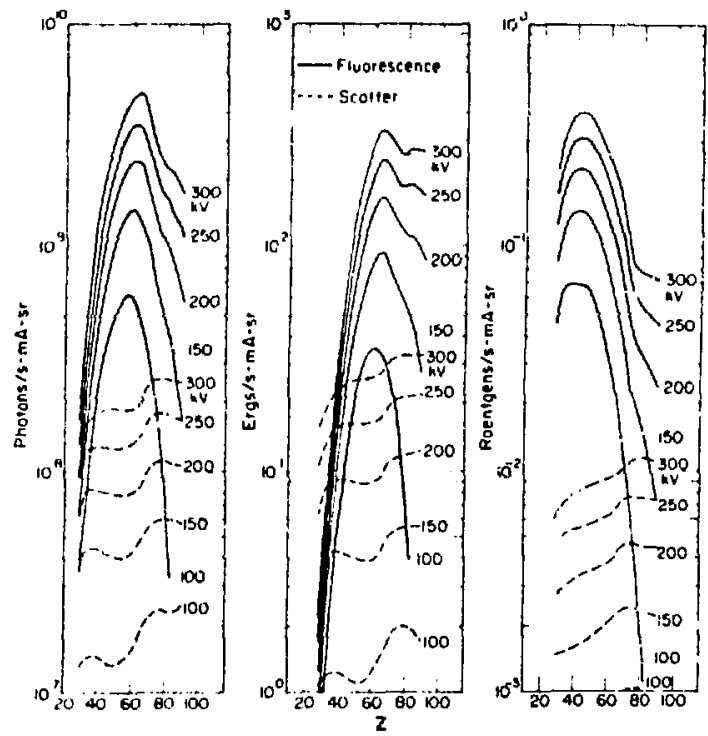

Fig. 25.

$K$ and scatter intensity as a function of $Z$. 


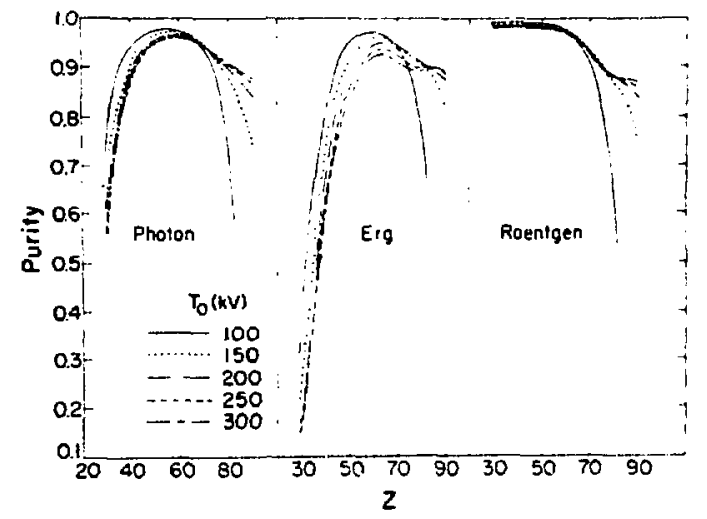

Fig. 26.

Purity as a function of $Z$.

and $T_{0}=100 \mathrm{kV}$, purity is 0.73 in photons and only 0.34 in ergs. In roentgens, purity is relatively consiant in the range $29 \leq Z \leq 64$, but decreases at higher $\mathbf{Z}$.

Figure 27 shows intensity variation with potential for fixed $\mathrm{Z}$, with $\mathrm{K}$ photon and scatter intensity in photons, ergs, and roentgens plotted as a function of $T_{0}$ for the 10 targets. The $K$ photon and scatter intensity curves increase with increasing $T_{0}$, the rise being more rapid berween 100 and $200 \mathrm{kV}$ than between 200 and $300 \mathrm{kV}$. Evidently, the curves would
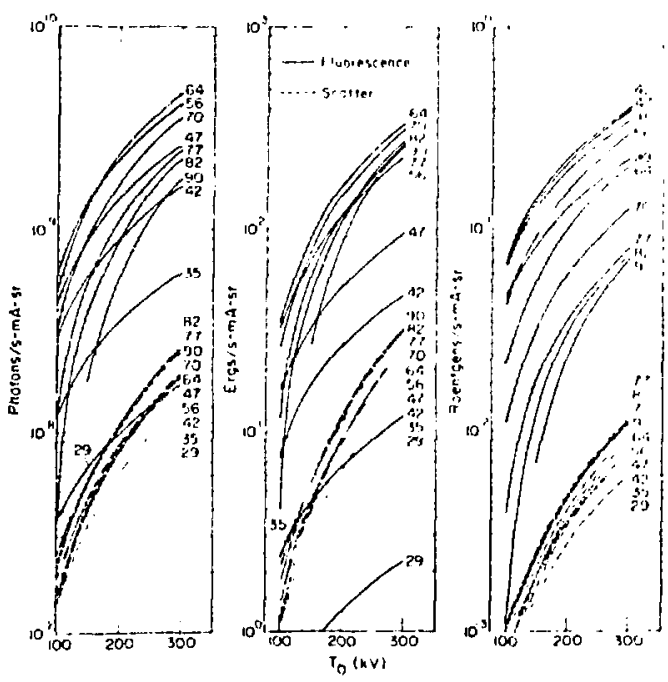

Fig. 27.

$K$ - and scatter intensity as a function of potential. continue to level off at still higher potentials. When the potential is increased from 100 to $300 \mathrm{kV}$, about a factor of 5 increase for $Z<50$ and a factor of 10 increase for $Z>50$ is obtained in the K-photon intensity, whereas an order of magnitude increase in scat ter intensity is obtained at all $Z$.

It is evident from Fig. 27 that in the $100.10300-\mathrm{kV}$ potential range the $x$-ray tube should be operated at the highest potential to maximize $K$-photon intensity. However, because scatter also increases with potential, purity of the radiation must be considered. Purity is plotted in Fig. 28 in roentgens and photons and in Fig. 29 in ergs as a function of overvoltage $\mathrm{U}_{1}=\mathrm{T}_{1} / \mathrm{T}_{\mathrm{K}}$, where $\mathrm{T}_{\mathrm{K}}$ is the secondary target K-edge energy. For $U_{0}<1$, K-ph ton intensity and purity are zero. Because the photoelectric coefficient is a maximum at the upper $K$ edge, for a given $\mathrm{Z}$, the purity curve rises rapidly for $\mathrm{U}_{0} \geq 1$. In roentgens, purity increases, reaches a maximum near $\mathrm{U}_{0}=3$, and remains relatively constant out io $\mathrm{U}_{b}=30$. In photons, the curves reach a maximum in the range $3<\mathrm{U}_{a}<5$ and then decrease. In ergs.
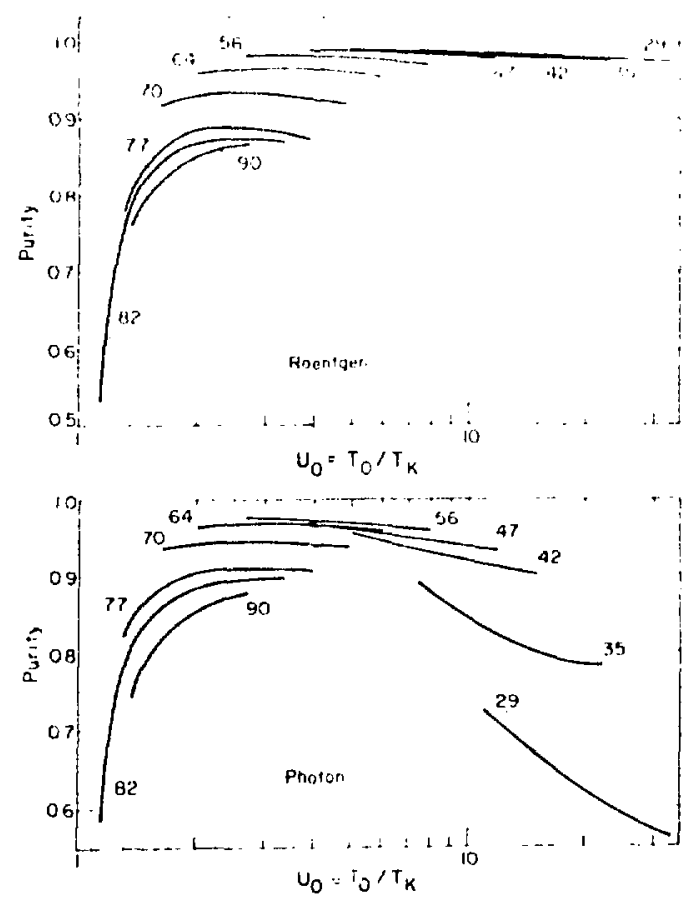

Fig. 28.

Purity in terms of roentgens and photons as a function of overuoltage. 


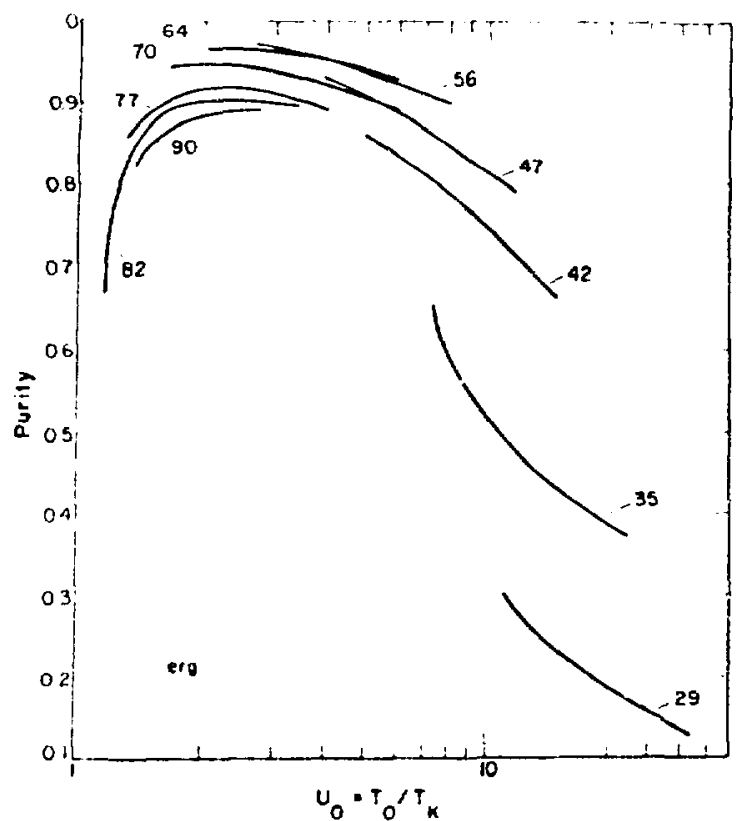

Fig. 29.

Purity in terms of ergs as a function of overunltage.

maximum purity is reached more rapidly, but the region of const ancy is in the narrower range $2<\mathrm{U}_{\mathrm{a}}<$ 3 and purity decreases more rapidly.

In summary, maximum $K$-photon intensity is obtained at maximum potential. In roentgens, maximum purity also occurs at the highest potential. Hence, a $300-\mathrm{kV}$ potential will give maximum intensity and purity for all 10 targets. At $300 \mathrm{kV}$, purity is $>0.95$ for $29 \leq Z \leq 64$, but gradually decreases for higher $Z$, and reaches a low of 0.87 for $Z=90$.

In photons, for $Z=29$, purity improves from 0.56 at $300 \mathrm{kV}$ to 0.73 at $100 \mathrm{kV}$. Simila:ly, for $Z=35$, purity improves from 0.78 at $300 \mathrm{kV}$ to 0.89 at 100 $\mathrm{kV}$. If the $\mathrm{K}$-photon intensity at $300 \mathrm{kV}$ is taken as 1.0. the fraction obtained at $100,150.200$, and 250 $\mathrm{kV}$ is about $0.16,0.3,0.5$, and 0.75 , respectively, for $Z<50$. Hence, purity improvement for $Z=29$ and 35 is achieved at the expense of a factor of 6 in intens:ty. For targets $42 \leq Z \leq 90$, purities of 0.88-0.96 are obtained at $300 \mathrm{kV}$.

In ergs, sutisfactory purity for the !owest $\mathrm{Z}$ targets cannot be obtained even with low potentials. For example. with a $100-k \mathrm{~V}$ potential, purities of only 0.30 and 0.65 are obtained with $Z=29$ and 35 , respectively. As 2 increases, purities improve so that higher potentials can be used. A $200-\mathrm{kV}$ potential provides purities of 0.74 and 0.85 for $Z=42$ and 47 , respectively. With a $300-\mathrm{kV}$ potential, purities of 0.89 to 0.93 are obtained for targets of $56 \leq Z \leq 90$.

\section{C. $\mathbf{K}_{\mathbf{\beta}}$ Filter}

Table IX lists the $K_{a}$ and $K_{\beta}$ energies of the 10 targets. The $K_{\alpha}$ and $K_{\phi}$ lines are separated by $<4$ $\mathrm{keV}$ and for $Z<50$. However, the separation increases with $Z$ and is $14 \mathrm{keV}$ at $Z=90$. A more monoenergetic source is required in calibration, if the instrument response is changing rapidly or $K$ edge siructure is to be resolved. The $K_{\beta}$ contribution can be reduced, with miniınum reduction in the $K_{\alpha}$. line, by using a filter with a K-edge energy between the $K_{a}$ and $K_{\sigma}$ energies. A list of $K_{\beta}$ filters which can be used with the 10 targets is given in Table IX. The table lists the $\mathrm{K}_{B}$-filter atomic number, $\mathrm{K}$-edge energy, and thickness that reduces the $K_{a}-t_{0} \cdot K_{a}$ ratio to 0.02 . Also, the fraction of the $K_{\alpha}$ intensity transmitted by the $K_{\alpha}$ filter is given.

To demonstrate how the $K_{f}$ filter alters the secondary target spectrum, calculated spectra are given for a low-Z (42) target in Fig. 30 and a high- $Z$ (82) target in Fig. 31, with and without a $K_{\theta}$ filter. With a $Z=42$ target, the $K_{\phi}$ filter $(Z=41)$ reduces the $K_{d}-$ to- $K_{a}$ ratio to 0.02 , decreases the $K_{a}$ intensity to one-half, and has little effect on the scatter intensity. With a $Z=82$ target, the $K_{d}$ filter $(Z=78)$ reduces the $K_{b}$-to- $K_{a}$ ratio to 0.02 , decreases the $K_{a}$ intensity to one-fourth, and appreciably reduces the scatter intensity.

$\mathrm{K}$ purity has been defined by the ratio $\left(\mathrm{I}_{\mathrm{K}_{\alpha}}+\right.$ $\left.I_{h_{\beta}}\right) /\left(I_{k_{\alpha}}+I_{k_{\beta}}+I_{s}\right)$, where $I_{k_{\alpha}} I_{k_{\beta}}$, and $I_{s}$ are the $K_{\alpha}$. $K_{w}$, and scatter intensities, respectively. If the $K_{d}$ line is considered a contaminant, the $K_{\alpha}$ purity is defined by the ratio $\left(I_{K_{\alpha}}\right) /\left(I_{k_{\alpha}}+I_{K_{\beta}}+I_{S}\right)$.

Tables X-XII list calculated values of $I_{k_{x x}}, I_{k_{p}}, I_{s}$. $K$ purity, and $K_{n}$ purity in photons, ergs, and roentgens, respectively for the 10 secondary targets $29 \leq \mathrm{Z} \leq 90$. Intensities were calculated for target thicknesses labeled 0.99 in Fig. 21.

In roentgens the scatter intensity $I_{S}$ is so small that the reduction of the $K_{B}$ line results in significant improvement in $K_{\alpha}$ purity for all 10 targets. In photons and ergs, however, the scatter intensity is 
TABLE IX

SECONDARY TARGET $\mathrm{K}_{B}$-FILTERS

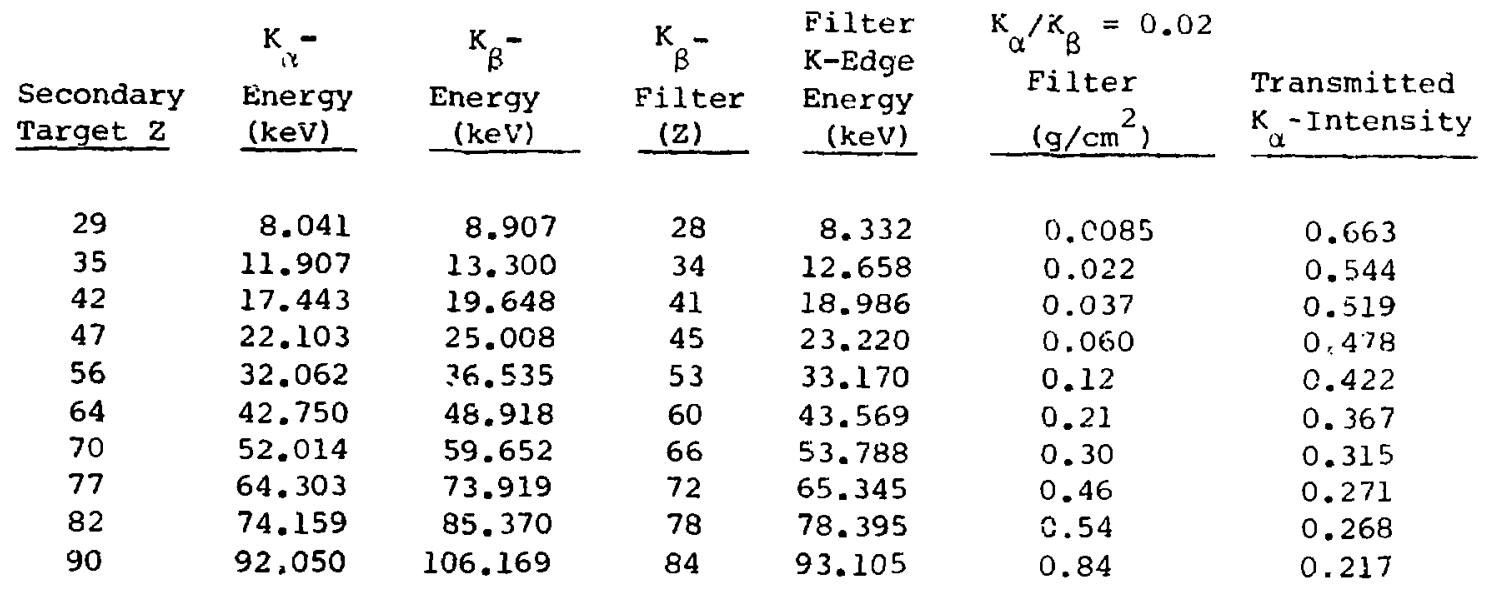

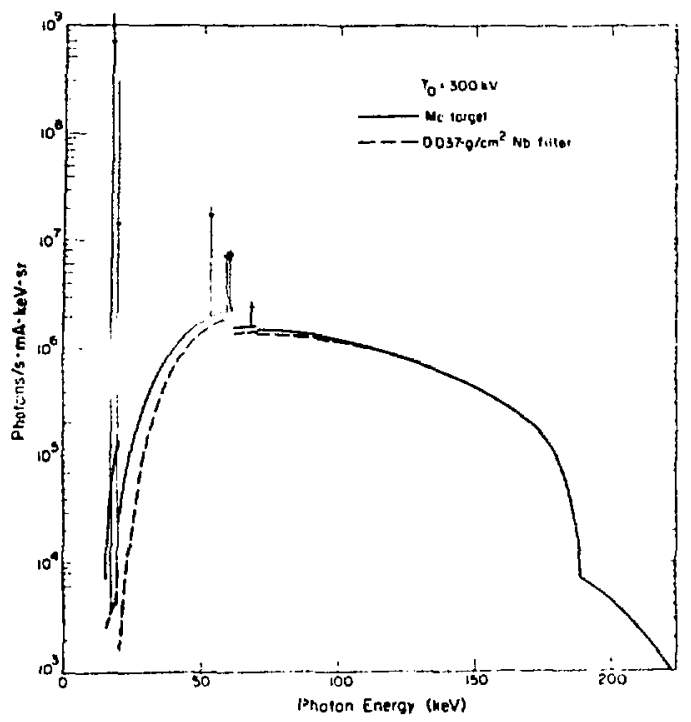

Fig. 30.

Calculated $Z=48$ sicondary target spectrum with and without $a Z=41 K_{B}$ filter. Molybdenum $K_{\alpha}(17.4 \mathrm{keV})$ and $K_{\beta}(19.6 \mathrm{keV})$ lines are shown superimposed on $90^{\circ}$ scattered spectrum. The coherently scattered molybdenum $K$ edge (20 keV), tungsten $K$ edge (69 $\mathrm{keV})$, and tungsten $K$ lines (59 and $68 \mathrm{keV}$ ) appear, as well as the incoherently scattered molybdenum $K$ edge ( $19 \mathrm{keV}$ ), tungsten $K$ edge ( 61 $\mathrm{keV}$ ), and tungsten $K$ lines (53 and $60 \mathrm{keV}$ ). Horizontal lines on line spectra indicate inten. sity peaks with $K_{\beta}$ filter.

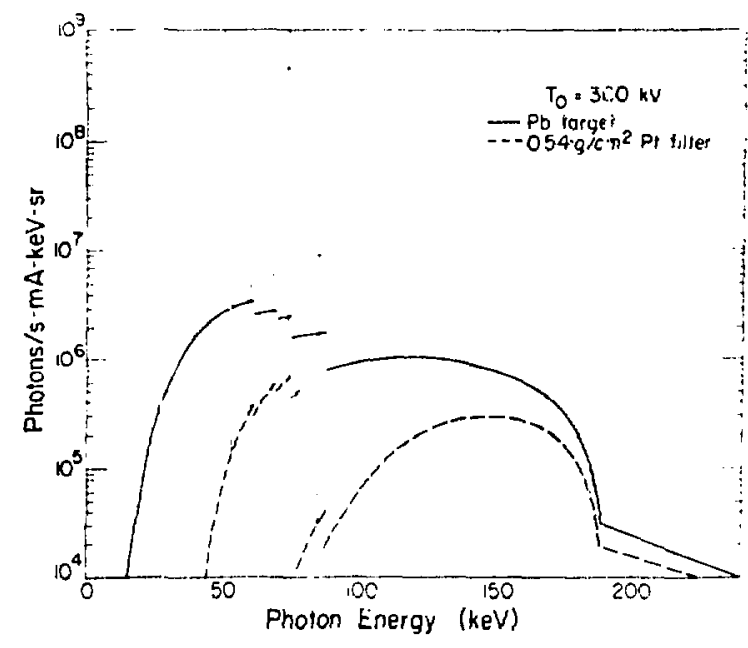

Fig. 31 .

Calculated $Z=82$ secondary target spectrum with and without $a Z=78 K_{\beta}$ filter. Lead $K_{n}-(74$ $\mathrm{keV})$ and $K_{B}(85 \mathrm{keV})$ lines are shown superimposed on $90^{\circ}$ scattered spectrum. The coherently scattered lead $K$ edge ( $88 \mathrm{keV}$ ), tungsten $K$ edge ( $69 \mathrm{keV}$ ), and tungsten $K$ lines (59 and 68 $\mathrm{keV}$ ) appear, as well as the incoherently scattered lead $K$ edge (75 keV), tungsien $K$ zdge (6) keV), and tungsten $K$ lines (53 and 60 $\mathrm{keV})$. Horizontal lines on line spectra indicate intensity peaks with $K_{\beta}$ filter. 
TABLE $X$

INTENSITY (photons/s-mA-sr) AND PURITY

OF SRCONDARY TARGETS WITH AND WITHOUT $x_{B}$-FILTER

With $x_{B}$-Piticer

\begin{tabular}{|c|c|}
\hline $\begin{array}{c}\text { Target } \\
2 \\
\end{array}$ & $\begin{array}{c}\text { Target } \\
\text { Thick- } \\
\text { ness } 2 \\
\left(g / \mathrm{cm}^{2}\right)\end{array}$ \\
\hline 29 & 0.06 \\
\hline 35 & 0.09 \\
\hline 42 & 0.12 \\
\hline 47 & 0.15 \\
\hline 56 & 0.20 \\
\hline 64 & 0.25 \\
\hline 70 & 0.32 \\
\hline 77 & 0.47 \\
\hline $8 ?$ & 0.53 \\
\hline 90 & 0.57 \\
\hline
\end{tabular}

$I_{X_{B}}$
$4.67 \times 10^{6}$
$1.86 \times 10^{8}$
$2.96 \times 10_{8}$
$5.05 \times 10^{8}$
$8.86 \times 10^{9}$
$1.03 \times 10^{8}$
$7.95 \times 10_{8}$
$5.78 \times 10_{8}$
$5.32 \times 10^{8}$
$\therefore .32 \times 10^{8}$

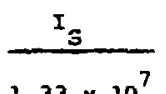

$1.33 \times 10_{7}^{7}$

$1.50 \times 10^{7}$

$1.84 \times 10_{8}^{8}$

1. $80=108$

$1.85 \times 10_{8}^{8}$

$1.97 \times 10$

$2.58 \times 10^{8}$

$2.56 \times 10^{\circ}$

$2.48 \times 1 \mathrm{C}$

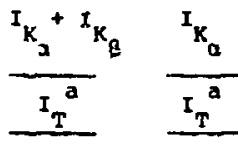

$0.726 \quad 0.630$

0.889

0.898

0.933

0.959

0.960

0.937

0.916

0.898

0.876

0.75

0.735

0.754

0.761

0.754

0.733

0.693

0.683

0.663

(2)

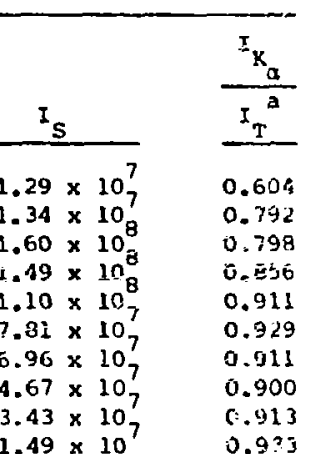


TARLE XI

INTENSITY (E. $\mathrm{xg} / \mathrm{s}-\Pi A-s r)$ AND PURITY OF SECONDARY TARGETS WITH AND WITHOUT $K_{\beta}$-FILTER

\begin{tabular}{|c|c|c|c|c|c|c|c|c|c|c|}
\hline \multirow[b]{2}{*}{$\begin{array}{c}\text { Target } \\
\mathrm{z}\end{array}$} & \multirow[b]{2}{*}{$\begin{array}{c}\text { Target } \\
\text { Thick- } \\
\text { ness } \\
\left(\mathrm{g} / \mathrm{cm}^{2}\right)\end{array}$} & \multirow[b]{2}{*}{$\begin{array}{c}\mathrm{T}_{\mathrm{O}} \\
(\mathrm{kV}) \\
\end{array}$} & & & & & \multirow[b]{2}{*}{$\mathrm{I}_{\alpha}$} & \\
\hline & & & $\mathrm{I}_{\alpha}$ & $\mathrm{I}_{\mathrm{B}}$ & $I_{S}$ & $\frac{I_{\alpha}+{ }^{I_{\alpha}} K_{\beta}}{I_{T}{ }^{a}}$ & & $\bar{I}_{\alpha}$ & $I_{S}$ & $\frac{I_{K_{\alpha}}}{I_{T}^{a}}$ \\
\hline 29 & 0.06 & 100 & 0.395 & 0.0663 & 1.05 & 0.305 & 0.261 & 0.261 & 1.02 & 0.203 \\
\hline 35 & 0.09 & 100 & 1.94 & 0.396 & 1.23 & 0.655 & 0.544 & 1.06 & 1.12 & 0.481 \\
\hline 42 & 0.12 & 200 & 20.6 & 5.11 & 8.95 & 0.742 & 0.594 & 10.7 & 7.90 & 0.568 \\
\hline 47 & 0.15 & 200 & 41.0 & 10.7 & 9.20 & 0.849 & 0.673 & 39.6 & 7.43 & 0.713 \\
\hline 56 & 0.20 & 300 & 175 & 51.6 & 25.5 & 0.899 & 0.694 & 73.9 & 18.0 & 0.789 \\
\hline 64 & 0.25 & 300 & 257 & 78.9 & 26.4 & 0.927 & 0.709 & 94.4 & 13.8 & 0.856 \\
\hline 70 & 0.32 & 300 & 238 & 75.9 & 31.0 & 0.910 & 0.690 & 75.0 & 11.8 & 0.847 \\
\hline 77 & 0.47 & 300 & 194 & 68.2 & 32.7 & 0.889 & 0.658 & 52.8 & 8.07 & 0.851 \\
\hline 82 & 0.53 & 300 & 201 & 72.9 & 33.0 & 0.892 & 0.655 & 53.8 & 6.07 & 0.880 \\
\hline 90 & 0.67 & 300 & 197 & 73.4 & 33.0 & 0.891 & 0.649 & 42.8 & 2.79 & 0.918 \\
\hline
\end{tabular}


INTENSITY $(R / s-m A-s r)$ AND PURITY OF SECONDARY TARGETS WITH AND WITHOUT $\mathrm{K}_{\beta}$-FILTER

\begin{tabular}{|c|c|c|c|c|c|c|c|c|c|c|}
\hline \multirow[b]{3}{*}{$\begin{array}{c}\text { Target } \\
z \\
\end{array}$} & \multirow{3}{*}{$\begin{array}{r}\text { Target } \\
\text { Thick- } \\
\text { ness } \\
\left(\mathrm{g} / \mathrm{cm}^{2}\right) \\
\end{array}$} & \multirow{3}{*}{$\begin{array}{r}T_{0} \\
(\mathrm{kV}) \\
\end{array}$} & \multirow[b]{3}{*}{$I_{\alpha}$} & \multirow[b]{3}{*}{$\mathbf{I}_{\mathbf{K}_{B}}$} & \multirow[b]{3}{*}{$\mathrm{I}_{\mathrm{S}}$} & & & \multicolumn{3}{|c|}{ With $\mathrm{K}_{\mathrm{B}}$-Filter } \\
\hline & & & & & & $\mathrm{I}_{\alpha}+\mathrm{I}_{\mathrm{K}}$ & $\mathrm{I}_{\mathrm{K}}$ & & & $\mathrm{I}_{\mathrm{K}}$ \\
\hline & & & & & & $I_{T}^{a}$ & $I_{T}{ }^{a}$ & $\mathrm{I}_{\mathrm{K}}$ & ${ }^{I} s$ & $I_{T}{ }^{a}$ \\
\hline 29 & 0.06 & 100 & 0.0411 & 0.00508 & 0.000625 & 0.987 & 0.878 & 0.0271 & 0.000594 & 0.962 \\
\hline 35 & 0.09 & 100 & 0.0598 & 0.00867 & 0.000653 & 0.991 & 0.865 & 0.0325 & 0.000561 & $0.96,7$ \\
\hline 42 & 0.12 & 300 & 0.346 & 0.0596 & 0.00793 & 0.981 & 0.837 & 0.179 & 0.00684 & 0.949 \\
\hline 47 & 0.15 & 300 & 0.334 & 0.0596 & 0.00847 & 0.979 & 0.831 & 0.159 & 0.00664 & 0.945 \\
\hline 56 & 0.20 & 300 & 0.247 & 0.0503 & 0.00897 & 0.971 & 0.806 & 0.104 & 0.00538 & 0.936 \\
\hline 64 & 0.25 & 300 & 0.166 & 0.0382 & 0.00958 & 0.955 & 0.776 & 0.0612 & 0.00414 & 0.922 \\
\hline 70 & 0.32 & 300 & 0.102 & 0.0260 & 0.0112 & 0.921 & 0.734 & 0.0322 & 0.00360 & 0.885 \\
\hline 77 & 0.47 & 300 & 0.0613 & 0.0192 & 0.0114 & 0.876 & 0.667 & 2.0167 & 0.00243 & 0.858 \\
\hline 82 & 0.53 & 300 & 0.0567 & 0.0194 & 0.0112 & 0.872 & 0.649 & 0.0152 & 0.00178 & 0.878 \\
\hline 90 & 0.67 & 300 & 0.0520 & 0.0195 & 0.0109 & 0.868 & 0.631 & 0.0113 & 0.000792 & 0.914 \\
\hline
\end{tabular}

${ }^{a} I_{T}=I_{K_{\alpha}}+I_{K_{B}}+I_{K_{S}}$. 
large. For low- $Z$ targets, the $K_{\beta}$ filter does not significantly reduce the scatter intensity (Fig. 30), and $K_{\alpha}$ purity is actually poorer with the $K_{\beta}$ filter because of the $K_{\alpha}$-line attenuation. For high- $Z$ targets, the $K_{\alpha}$ filter reduces the scatter intensity (Fig. 31), and $K_{\alpha}$ purity is improved by the $K_{\beta}$ filter.

When monochromaticity of the $\mathrm{K}$ lines is not important, the $K_{j}$ filter need not be used, because $K$ purity is better than $K_{a}$ purity for all targets except $\mathrm{Z}=82$ and 90 . The small improvement in purity of these targets is achieved at the expense of $K_{c k}$ intensity, which is reduced by about a factor of 4 .

\section{Discussion}

Because theory and measurement agreed within $20 \%$, it was assumed that theory could be used to estimate target thicknesses, potentials, and $K_{\beta}$ filters which would optimize K-photon intensity and purity. Tables X-XII summarize these estımates.

The intensity and purity of the lowest and highest $\mathrm{Z}$ targets leave something to be desired. Limitations on the achievable intensity and purity were imposed by the primary source used in the measurements and were assumed in the calculations. This can be seen more clearly in Fig. 32, where conversion efficiency in photons, ergs, and roentgens is plotted as a function of $\mathrm{Z}$ for five potentials in the $100-$ to $300-\mathrm{kV}$ range. Conversion efficiency is defined as the ratio of $\mathrm{K}$-photon intensity emitted by the secondary target to the primary photon intensity incident on the target. As with purity, the efficiency depends on the intensity units being most efficient for roentgens and least efficient for ergs. Maximum efficiencies of 2, 3 , and $7 \%$ are obtained for the middle- $Z$ targets in ergs, photons, and roentgens, respectively. Efficiency decreases for both low- and high- $Z$ targets.

It is informative to inquire into the bell-shaped appearance of the conversion efficiency curves. If we examine Eq. (9). which describes the $K_{\alpha}$ intensity, the principal terms of interest are $\omega_{K}, I_{\text {primary }}$, and $\tau=\tau_{k} /\left(\mu_{k}+\mu_{k_{\alpha}}\right)$. The exponential term and its in. fluence on intensity and purity were discussed in Sec. V.A. The $\sigma_{\mathrm{K}} / \sigma_{\mathrm{T}}$ term is approximately 0.8 for a!l $Z$. The fluorescent yield, $\omega_{K}$, is $>0.9$ and roughly cunstant for $Z \geq 56$ but decreases at lower $Z$ to a low of 0.455 for $Z=29$. Hence, the decrease in efficiency for $\mathrm{Z}<50$ can be attributed in part to the decrease in $\omega_{K}$ with lower $Z$.

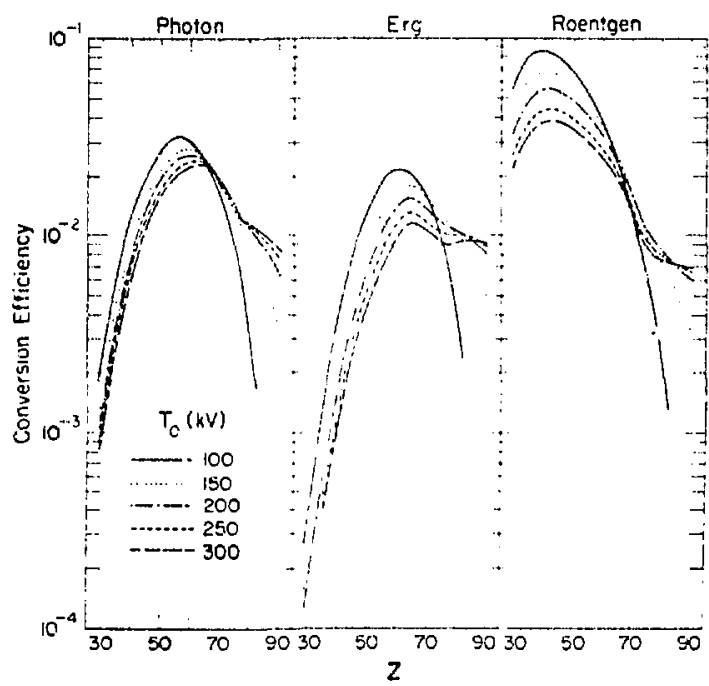

Fig. 32.

Conversion efficiency as a function of $Z$. The ordinate is the ratio of $K$ intensity emitted by target-to-primary intensity incident on target.

But the shape of the efficiency curves is influenced primarily by $\tau, I_{\text {primary, }}$ and the location of the target $\mathrm{K}$ edge. For example, $\tau$ for $Z=29$ is about 0.8 at the 9-keV K edge, but falls to 0.08 at $40 \mathrm{keV}$ and to 0.008 at $90 \mathrm{keV}$. Because there are relatively few photons below $40 \mathrm{keV}$ in $\mathrm{I}_{\text {primary }}$, the $\mathrm{K}$-photon yield is low for $\mathrm{Z}=29$. This implies that the yield can be increased by using a primary beam with more photons in the 9 to $40 . \mathrm{keV}$ region, e.g., one operating at a potential of $50 \mathrm{kV}$. For $\mathrm{Z}=42,+$ is 0.8 at the $20-\mathrm{keV} \mathrm{K}$ edge and falls to 0.08 at $80 \mathrm{keV}$. Because there are more primary photons in the 20 - to $80-\mathrm{keV}$ region than in the 9 . to $40-\mathrm{keV}$ region, the $Z=42$ photon yield is considerably larger than the $Z=29$ yield. Thus, as $Z$ increases, $\tau$ remains significant over a longer photon region and the $\mathrm{K}$-photon efficiency increases. For $\mathrm{Z}$ $=64, r=0.8$ at the $50-\mathrm{keV} \mathrm{K}$ edge and 0.08 at 180 $\mathrm{keV}$, giving a maximum yield for the $I_{\text {primury }}$ used in these calculations. As $Z$ is increased further, $T$ remains significant over a longer photon region, but the $\mathrm{K}$-edge location is increasing with energy, reducing the number of usable primary photons. For $Z=$ $90, \tau$ is 0.8 at the $110-\mathrm{keV} \mathrm{K}$ edge and decreases to 0.1 at $290 \mathrm{keV}$. But only photons above the $\mathrm{K}$ edge can produce $\mathrm{K}$ photons, so that all the primary photons below $110 \mathrm{keV}$ are lost. Thus, the efficiency decreases. To improve the high- $Z$ efficiency would require primary potentials $>300 \mathrm{kV}$. 
Therefore, the assumed primary source for the calculations imposed limitations on the intensity and purity that could be achieved and resulted in the bell-shaped elficiency curve. Calculations indicate that order of magnitude increases in efficiency could be achieved with lower $Z$ targets if the primary source had a iremsstrahlung continuum with lighr-inherent filtration and operating potentials of $30-60 \mathrm{kV}$. Similarly, the efficiency of high-Z targets could be improved by a factor of 2 if a primary source with a $500-\mathrm{kV}$ pctential were used.

\section{REFERENCES}

1. S. K. Allison and W. Duane, "Experimental Determination of the Critical Excitation Frequency for the Production of Fluorescent X-Radiation," Proc. Nat. Acad. Sci. 11, 485 (1925).

2. A. H. Compton, "The Efficiency of Production of Fluorescent X-Rays," Philos. Mag. 8, 961 (1929).

3. H. Kustier, "Die Erzeugung Intensiver Monochromatischer Röntgenstrahlen mit Hilfe Technischer Röhren Ohne Spektralapparat," Z. Physik 70. 324 (1931).

4. T. H. Rugers, "Production of Monorhromatic XRadiation for Microradiography by Excitation of Fluorescent Characteristic Radiation." J. Appl. Phys. 23, 881 (1952).

5. H. R. Splet tstosser and H. E. Seemann, "Application of Fluorescence X-Rays to Metallurgical Microradiography," J. Appl. Phys. 23, 1217 (1952).

6. .J. L. Gaines, P. J. Ebert, and G. R. Leipelt, "Detector Calibration Techniques, X-Ray Machine Intensities and Fluorescent X-Ray Spectrum Catalog," Lawrence livermore Laboratory report UCID-16091 (November 1967).
7. R. L. Kathren, "Spectral and Output Measurements of a Wide Beam K-Fluorescence Radiator," Lawrence Livermore Laboratory report UCRL-14151 (March 1965).

8. R. L. Kathren, F. L. Rising, and H. V. Larson, "K-Fluorescence X-Rays: a Multi-Use Tool for Health Physics," Health Phys. 21, 285 (1971).

9. B. J. Krohn, W. B. Chambers, and E. Storm. "The Photon Energy Response of Several Commercial Ionization Chambers, Geiger Counters, and Thermoluminescent Detectors," Los Alamos Scientific Laboratory report LA-4052 (February 1969).

10. H. V. Larson, J. T. Myers, and W. C. Roesch. "Wide-Beam Fluorescent X-Ray Source," Nucleonics 13. 100 (1955).

11. J. H. McCrary, L H. Ziegler, and L. D. Looney, "Calibration and Use of the 75-kVP X-Ray Facility," EG\&G reports L-229 (1968) and L-940 (1969).

12. H. E. Seemann, "Spectral Sensitivity of Two Commercial X-Ray Films between 0.2 and 2.5 Angstroms," Rev. Sci. Instr. 21, 314 (1950).

13. E. Storm and S. Shlaer, "Development of Energy-Independent Film Badges with MultiElement Filters," Health Phys. 11, 1127 (1965).

14. E. F. Kaelble, Handbook of X-Rays (McGrawHill Book Co., New York, 1967), Part 4.

15. E. Storm, H. I. Israel, and D. W. Lier, "X-Ray Spectral Distributions from Thick Tungsten Targets in the Energy Range 12 to $300 \mathrm{kV}$," Aduances in $X$. Ray Analysis (Plenum. New York, 1971) Vol. 15. p. 339. 
16. H. I. Israel, D. W. Lier, and E. Storm, "Comparison of Detectors Used in the Measurement of 10 to $300 \mathrm{keV}$ X-Ra Spectra," Nucl. Instr. Meth. 91, 141 (1971).

17. E. Storra, "Calculated Bremsstrahlung Spectra from Thick Tungsten Targets," Phys. Rev. A5, 2328 (1972).

18. E. Storm, "Emission of Characteristic $L$ and $K$ Radiation from Thick Tungsten Targets," J. Appl. Phys. 43, 2790 (1972).
19. D. T. Cromer, to be published in Acta Crystallographica.

20. D. T. Cromer ciidd J. B. Mann, "Compton Scattering Factors for Spherically Symmetric Free Atoms." J. Chem. Phys. 47, 1892 (1967).

21. D. T. Cromer, "Compton Scattering Factors for Aspherical Free Atoms," J. Chem. Phys. 50. 485i (1969!.

22. E. Storm and H. I. Israel, "Photon Cross Sections from $1 \mathrm{keV}$ to $100 \mathrm{MeV}$ for Elements $\mathrm{Z}=1 \mathrm{to} \mathrm{Z}$ = 100." Nucl. Data Tables A7, 565 (1970). 